\title{
13. MAGNETIC, BATHYMETRIC, SEISMIC REFLECTION, AND POSITIONING DATA COLLECTED UNDERWAY ON GLOMAR CHALLENGER, LEG 32
}

\author{
Roger L. Larson and Yves Lancelot, Lamont-Doherty Geological Observatory, Palisades, New York \\ James V. Gardner, Scripps Institution of Oceanography, La Jolla, California \\ and \\ Ralph Moberly, Institute of Geophysics, University of Hawaii, Honolulu, Hawaii
}

\section{INTRODUCTION}

The track of Leg 32, which left Hakodate, Japan on 16 August 1973 and arrived at Honolulu, Hawaii on 10 October 1973, is shown in Figure 1. Site numbers and progressive distance in hundreds of nautical miles along the track are annotated. Table 1 is a list of the positioning information acquired underway by the satellite navigation system used to plot this track. Errors in these positions are generally substantially less than 1 nautical mile (Talwani et al., 1966). Table 1 also shows distance in nautical miles along the track and the speed and course maintained between that navigation point and the subsequent one. Also listed in Table 1 are the regional magnetic field values computed at each navigation point from the coefficients of Cain et al. (1968) and used to determine the magnetic anomaly profiles in Figures 2 through 7.
Figures 2 through 7 show the magnetic anomaly and bathymetric data plotted as functions of time, distance, latitude, and longitude with distance plotted as the linear function. These data have been reduced using the computer programs of Talwani (1969). The vertical scales in Figures 2 and 7 show magnetic anomaly values in gammas under " $\mathrm{M}$ " and depth in uncorrected fathoms assuming a sound speed of 800 fathoms/sec under "D." The magnetic anomaly profile is the darker of the two traces. At the top of the figures from top to bottom are annotated time in days, time in hours, latitude in degrees, and longitude in degrees. Along the bottom of the figures all navigation points are marked and occasional ones are annotated along with the course and speed that was subsequently maintained. On the bottommost scale at the bottom of the figures the distance along the track in nautical miles is shown. The site locations, significant bathymetric features, and magnetic

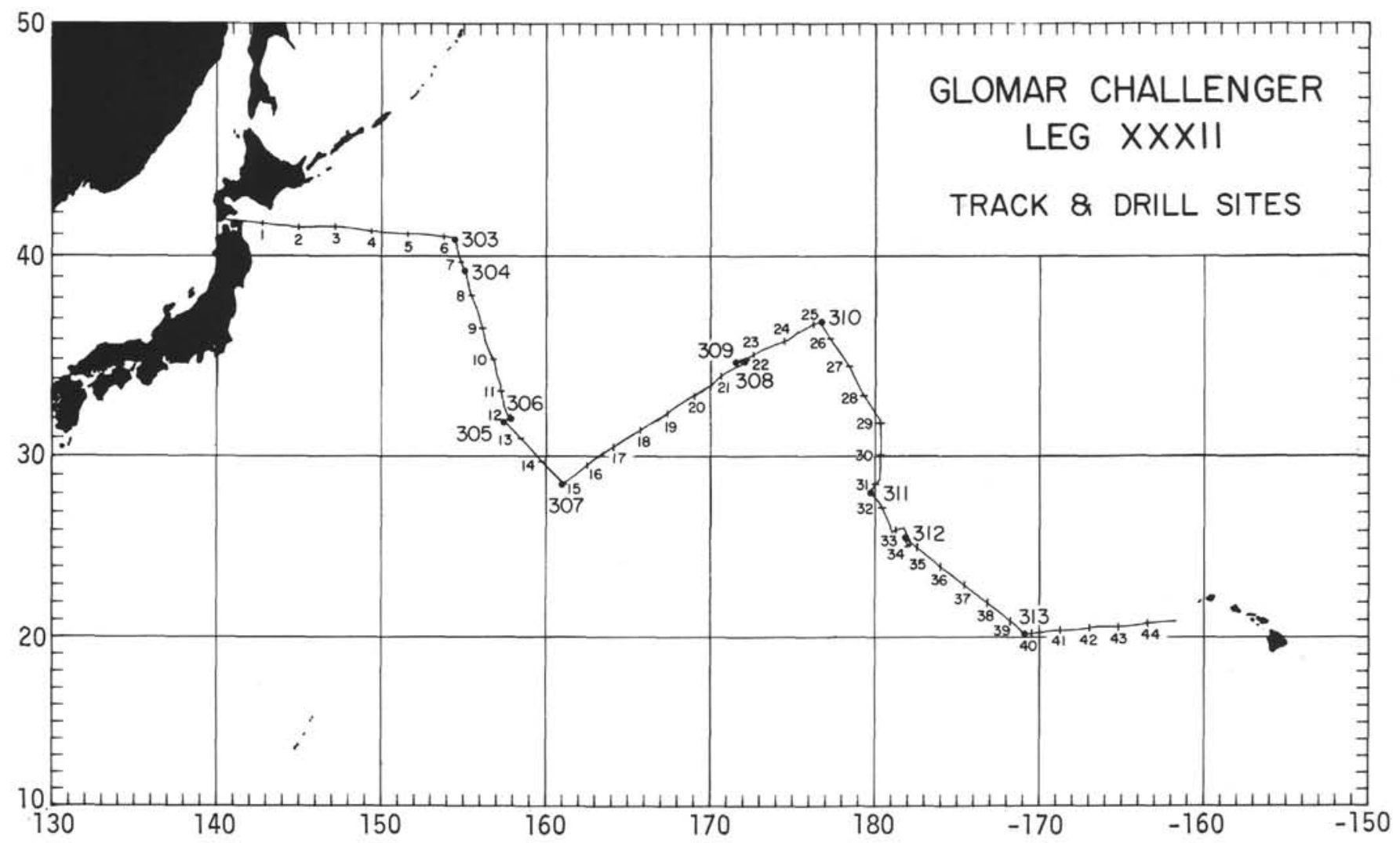

Figure 1. Track chart for Leg 32 of Glomar Challenger from Hakodate, Japan to Honolulu, Hawaii. Dots and larger numbers are drill site locations. Smaller numbers are distance along track in hundreds of nautical miles. 
anomaly identifications from Larson and Chase (1972) and Larson and Pitman (1972) are also annotated on the profiles.

Profiles in the second series of figures (Figures 8 through 27) are the seismic reflection records shown as a linear function of time. Depth is annotated on the sides of the profiles in reflection times. One second on the profile equals 400 nominal fathoms water depth. The bottoms of the profiles are annotated with the time in days and hours, and speed and the heading maintained. Distances along the ship's track, in hundreds of nautical miles, and site locations are plotted at the tops of the profiles. The sound source for these data was generally two airguns with $20-$ and $30-i n .^{3}$ firing chambers. The data were recorded on dry paper EDO recorders employing a 10-sec sweep rate. Note that on the first set of geophysical profiles (Figures 2 through 7) time and distance along the track increase from left to right, but on the seismic reflection record (Figures 8 through 27) time and distance increase from right to left.

\section{NARRATIVE}

After leaving Hakodate, Japan, the profile passes across the thickly ponded and layered sediments of the Japanese shelf and slope and drops abruptly to the axis of the Kuril Trench at $210 \mathrm{n} \mathrm{mi} \mathrm{(nautical} \mathrm{miles).} \mathrm{The}$ bathymetric high just beyond the trench axis at $246 \mathrm{n} \mathrm{mi}$ is the flank of Erimo (Sisoev) Seamount. Beyond Erimo Seamount the profile passes out onto the deep-sea floor where 300-500 meters of layered sediment overlies a relatively flat basement reflector for approximately 360 $\mathrm{n}$ mi then abruptly changes to a rough basement reflector. The profile out to Site 303 at $632 \mathrm{n}$ mi runs almost due east and is nearly parallel to the grain of the bathymetry and magnetic anomalies, although several fracture zones are crossed.

After Site 303 the profile runs south-southeast across the strike of a very well-defined M4 to M9 magnetic sequence to Site 304 at $726 \mathrm{n} \mathrm{mi}$. The slightly rougher nature of the basement reflector along this section reflects this cross-strike heading. The drilling results at Sites 303 and 304 demonstrate that the basement reflector on the reflection records is not the top of the volcanic rocks, but rather is a chert layer that overlies the volcanics there by a few tens $(\sim 50)$ of meters. This becomes apparent beyond Site 304 as the profile continues south to Shatsky Rise. As the profile approaches Shatsky Rise, the chert reflector and true basement reflector diverge revealing a thickening layer of carbonate that lies between the chert and basalt. This demonstrates the time-transgressive nature of the chert layer which becomes younger to the south and marks the passage of the Pacific plate across the equatorial zone of productivity. The faintly layered interval that overlies the opaque layer represents most of the Tertiary sediments. The thickness of this interval is seen on the profiles to diminish regularly toward the south. The thicker accumulation observed in the northernmost areas results from the influence of the zone of high productivity associated with the Kuroshio current system as well as the proximity of volcanic centers along the Kuril-Japan subduction zones. This interpretation is confirmed by the drilling results from Sites 303 and 304 . The chert layer in some places is a smoothed version of the underlying basement surface, but elsewhere is nearly flat-lying. Because the top of the opaque layer has been found to correspond to a 50-60 m.y. hiatus at Sites 303 and 304 , it is possible that the flatness of this horizon results at least in part from strong bottom-current activity. Magnetic anomalies along this section of the track are not obvious, but should range between M10 and M17.

The sea floor rises to about 3000 meters on top of Shatsky Rise, which is covered by 500 to 800 meters of layered sediments. The opaque layer loses its character as the chert becomes diluted in thick carbonate accumulations. These sediments pinch out on the flanks of the rise and are partially breached in the center by what appears to be a levee and channel feature 200 meters deep and $20 \mathrm{~km}$ wide centered at $1180 \mathrm{n} \mathrm{mi}$. The magnetic anomalies across Shatsky Rise are generally of smaller widths which reflect shallower sources, but are not correlatable with deep-sea magnetic lineation sequences. The sediments at Site 305 appear to be the entire Shatsky Rise sequence with two strong interval reflectors in the lower half of the section, whereas the section at Site 306 has the lower half of the former section exposed, apparently by erosion.

Leaving Site 306 the profile crosses the faulted southern flank of Shatsky Rise and passes onto the deep-sea floor where the upper opaque or chert layer lies nearly at the sea floor. Faint traces of the lower opaque or volcanic basement layer can be seen at about 300 meters subbottom. Site 307 is located at $1498 \mathrm{n} \mathrm{mi}$ in a small pocket of transparent sediment overlying the chert sequence.

The profile between Sites 307 and 308 is uniformly the same sedimentary sequence with the chert layer near or at the sea floor. The extremely thin or absent upper transparent layer reflects the transit of the Pacific plate in the area of very low productivity north of the equator, although the thinness might have been somewhat aggravated by widespread vigorous bottom circulation during the early Tertiary. An excellent magnetic anomaly profile is present here showing anomalies M21 to M4 with an interruption in the middle of the sequence between M12 and M15 (1700-1840 n mi). This magnetic interruption occurs over a section of sea floor rougher than the surrounding area and could reflect the oblique crossing of a fracture zone. The magnetic profile shows an especially good M4 to M11 sequence with M10a appearing as three characteristic, positive anomalies at $1900 \mathrm{n} \mathrm{mi}$.

The profile in the vicinity of Sites 308 and 309 shows three crossings of Koko Guyot, near the southern end of the Emperor Seamount chain. Here the sea floor shoals to as little as 700 meters, and the profiler reveals a thick coral cap on the central portion of the guyot. Very little sediment is revealed by the profiler on the flanks of the guyot crest.

The echo sounder reveals that the deep-sea floor is significantly shallower $(\sim 750 \mathrm{~m})$ east of Koko Guyot than west of that feature. The basement surface is not obvious on the profiler on either side of the seamount, so it is not known if this reflects a significantly shallower 
basement to the east, or a thicker sediment accumulation. A gravity profile in the vicinity of the Leg 32 track shows the deflection curve across Koko Guyot to be symmetric (Watts and Cochran, in press). Thus, it is likely that the crust both east and west of Koko is compensated and that the anomalously shallow depth results from other tectonic causes.

Hess Rise is a relatively shallow area broken by what appear to be large normal faults $(2420-2520 \mathrm{n} \mathrm{mi})$ that trend north-northwest across the feature. Where undisturbed, the basement reflector is flat-lying and underlies about 300 meters of layered sediment. Leaving Site 310 on Hess Rise, the track runs along the southern portion of the rise where variable sediment cover as thick as 400 meters is observed. At $2800 \mathrm{n}$ mi the track crosses the Mendocino Escarpment which occurs as a greater than $3 \mathrm{~km}$ change in depth.

The seamount crossed at $3170 \mathrm{n} \mathrm{mi}$ is part of the Hawaiian Seamount chain and is the source for the archipelagic apron on which Site 311 was drilled. Between Site 311 (3136 n mi) and Site 312 (3446 n mi) the track crosses and recrosses magnetic anomalies M1, $\mathrm{M} 2$, and M3 that are not labeled on the magnetic profile. Between Site 312 and Site 313 the track runs subparallel to and south of the Hawaiian Seamount chain. At about $3900 \mathrm{n} \mathrm{mi}$ the province of the MidPacific Mountains is encountered. Site 313 is located in a shallow saddle between two seamounts within the
Mid-Pacific Mountains. The profile leaves the MidPacific Mountains at $4220 \mathrm{n} \mathrm{mi}$ and the sea floor becomes uniformly smooth and underlain by reflective sediments of the Hawaiian archipelagic apron. This portion of the track is also subparallel to the Hawaiian Seamount chain. The smooth magnetic profile in this area is characteristic of the magnetic quiet zone.

\section{REFERENCES}

Cain, J.C., Hendricks, S:, Daniels, W.E., and Jensen, J.C., 1968. Computation of the main geomagnetic field from spherical harmonic expansions: Data User's Note NSSDC68-11, Greenbelt, Md.

Larson, R.L. and Chase, C.G., 1972. Late Mesozoic evolution of the western Pacific Ocean: Geol. Soc. Am. Bull., v. 83, p. 3627-3644.

Larson, R.L. and Pitman, W.C., III, 1972. Worldwide correlation of Mesozoic magnetic anomalies, and its implications: Geol. Soc. Am. Bull., v. 83, p. 3645-3662.

Talwani, M., 1969. A computer system for the reduction, storage, and display of underway data acquired at sea: Lamont-Doherty Geol. Obs. of Columbia Univ., Tech. Rept. 1, CU-1-69 N00014-67-A-0108-0004, p. 348.

Talwani, M., Dorman, J., Worzel, J.L., and Bryan, G.M., 1966. Navigation at sea by satellite: J. Geophys. Res., v. 71, p. $5891-5902$.

Watts, A.B. and Cochran, J.R., in press. Gravity anomalies and flexure of the lithosphere along the Hawaiian-Emperor Seamount Chain: Geophys. J. Roy. Astr. Soc. 
TABLE 1

List of Navigation Points for Underway Portion of Leg 32 of Glomar Challenger (Also

Tabulated are Distance Along Track, Courses and Speeds Maintained Between Navigation Points, and Regional Magnetic Field Values)

\begin{tabular}{|c|c|c|c|c|c|c|c|c|c|c|}
\hline Day & Mon & Year & $\mathrm{TZ}$ & Time & Latitude & Longitude & Distance & Speed & Course & Regional Mag \\
\hline 15 & 8 & 1973 & 0.0 & 2244 & $41^{\circ} 40.7^{\prime}$ & $140^{\circ} 36.7^{\prime}$ & 0.0 & 3.2 & 178 & 49203 \\
\hline 15 & 8 & 1973 & 0.0 & 2249 & $41^{\circ} 40.4^{\prime}$ & $140^{\circ} 36.7^{\prime}$ & 0.3 & 2.7 & 177 & 49200 \\
\hline 15 & 8 & 1973 & 0.0 & 2253 & $41^{\circ} 40.3^{\prime}$ & $140^{\circ} 36.7^{\prime}$ & 0.4 & 11.9 & 101 & 49198 \\
\hline 15 & 8 & 1973 & 0.0 & 2254 & $41^{\circ} 40.2^{\prime}$ & $140^{\circ} 37.0^{\prime}$ & 0.6 & 11.6 & 101 & 49197 \\
\hline 15 & 8 & 1973 & 0.0 & 2345 & $41^{\circ} 38.3^{\prime}$ & $140^{\circ} 49.9^{\prime}$ & 10.5 & 12.2 & 89 & 49113 \\
\hline 15 & 8 & 1973 & 0.0 & 000 & $41^{\circ} 38.4^{\prime}$ & $140^{\circ} 54.0^{\prime}$ & 13.5 & 12.6 & 90 & 49093 \\
\hline 15 & 8 & 1973 & 0.0 & 014 & $41^{\circ} 38.4^{\prime}$ & $140^{\circ} 57.9^{\prime}$ & 16.5 & 13.1 & 86 & 49073 \\
\hline 15 & 8 & 1973 & 0.0 & 036 & $41^{\circ} 38.7^{\prime}$ & $141^{\circ} 4.3^{\prime}$ & 21.3 & 12.9 & 93 & 49044 \\
\hline 16 & 8 & 1973 & 0.0 & 210 & $41^{\circ} 37.6^{\prime}$ & $141^{\circ} 31.3^{\prime}$ & 41.4 & 12.9 & 96 & 48897 \\
\hline 16 & 8 & 1973 & 0.0 & 239 & $41^{\circ} 36.9^{\prime}$ & $141^{\circ} 39.6^{\prime}$ & 47.7 & 7.1 & 96 & 48848 \\
\hline 16 & 8 & 1973 & 0.0 & 245 & $41^{\circ} 36.8^{\prime}$ & $141^{\circ} 40.5^{\prime}$ & 48.4 & 7.5 & 96 & 48843 \\
\hline 16 & 8 & 1973 & 0.0 & 246 & $41^{\circ} 36.8^{\prime}$ & $141^{\circ} 40.7^{\prime}$ & 48.5 & 8.1 & 95 & 48842 \\
\hline 16 & 8 & 1973 & 0.0 & 259 & $41^{\circ} 36.6^{\prime}$ & $141^{\circ} 43.0^{\prime}$ & 50.3 & 12.0 & 96 & 48829 \\
\hline 16 & 8 & 1973 & 0.0 & 432 & $41^{\circ} 34.8^{\prime}$ & $142^{\circ} 7.7^{\prime}$ & 68.8 & 10.9 & 97 & 48687 \\
\hline 16 & 8 & 1973 & 0.0 & 1050 & $41^{\circ} 26.0^{\prime}$ & $143^{\circ} 38.7^{\prime}$ & 137.5 & 11.2 & 95 & 48145 \\
\hline 16 & 8 & 1973 & 0.0 & 1150 & $41^{\circ} 25.0^{\prime}$ & $143^{\circ} 53.6^{\prime}$ & 148.8 & 11.2 & 91 & 48062 \\
\hline 16 & 8 & 1973 & 0.0 & 1236 & $41^{\circ} 24.9^{\prime}$ & $144^{\circ} 5.1^{\prime}$ & 157.4 & 11.2 & 94 & 48004 \\
\hline 16 & 8 & 1973 & 0.0 & 1350 & $41^{\circ} 240^{\prime}$ & $144^{\circ} 23.4^{\prime}$ & 171.2 & 11.2 & 111 & 47905 \\
\hline 16 & 8 & 1973 & 0.0 & 1425 & $41^{\circ} 21.7^{\prime}$ & $144^{\circ} 31.6^{\prime}$ & 177.7 & 10.7 & 94 & 47842 \\
\hline 16 & 8 & 1973 & 0.0 & 1446 & $41^{\circ} 21.5^{\prime}$ & $144^{\circ} 36.6^{\prime}$ & 181.5 & 11.1 & 96 & 47815 \\
\hline 16 & 8 & 1973 & 0.0 & 1558 & $41^{\circ} 20.1^{\prime}$ & $144^{\circ} 54.3^{\prime}$ & 194.8 & 10.3 & 96 & 47714 \\
\hline 16 & 8 & 1973 & 0.0 & 1634 & $41^{\circ} 19.4^{\prime}$ & $145^{\circ} 2.5^{\prime}$ & 201.0 & 10.4 & 93 & 47667 \\
\hline 16 & 8 & 1973 & 0.0 & 1700 & $41^{\circ} 19.1^{\prime}$ & $145^{\circ} 8.5^{\prime}$ & 205.5 & 9.6 & 86 & 47636 \\
\hline 16 & 8 & 1973 & 0.0 & 1742 & $41^{\circ} 19.6^{\prime}$ & $145^{\circ} 17.4^{\prime}$ & 212.2 & 9.8 & 84 & 47597 \\
\hline 16 & 8 & 1973 & 0.0 & 1930 & $41^{\circ} 21.5^{\prime}$ & $145^{\circ} 40.7^{\prime}$ & 229.8 & 9.6 & 84 & 47502 \\
\hline 16 & 8 & 1973 & 0.0 & 2022 & $41^{\circ} 22.3^{\prime}$ & $145^{\circ} 51.7^{\prime}$ & 238.1 & 10.2 & 85 & 47456 \\
\hline 16 & 8 & 1973 & 0.0 & 2108 & $41^{\circ} 23.0^{\prime}$ & $146^{\circ} 2.1^{\prime}$ & 246.0 & 6.8 & 85 & 47413 \\
\hline 16 & 8 & 1973 & 0.0 & 2118 & $41^{\circ} 23.1^{\prime}$ & $146^{\circ} 3.6^{\prime}$ & 247.1 & 7.4 & 93 & 47407 \\
\hline 16 & 8 & 1973 & 0.0 & 2200 & $41^{\circ} 22.8^{\prime}$ & $146^{\circ} 10.5^{\prime}$ & 252.3 & 7.4 & 91 & 47371 \\
\hline 16 & 8 & 1973 & 0.0 & 2346 & $41^{\circ} 22.5^{\prime}$ & $146^{\circ} 28.0^{\prime}$ & 265.4 & 7.6 & 90 & 47283 \\
\hline 17 & 8 & 1973 & 0.0 & 000 & $41^{\circ} 22.5^{\prime}$ & $146^{\circ} 30.4^{\prime}$ & 267.2 & 7.2 & 90 & 47272 \\
\hline 17 & 8 & 1972 & 0.0 & 008 & $41^{\circ} 22.5^{\prime}$ & $146^{\circ} 31.6^{\prime}$ & 268.1 & 10.3 & 91 & 47266 \\
\hline 17 & 8 & 1973 & 0.0 & 136 & $41^{\circ} 51.8^{\prime}$ & $146^{\circ} 51.8^{\prime}$ & 283.3 & 9.9 & 90 & 47166 \\
\hline 17 & 8 & 1973 & 0.0 & 200 & $41^{\circ} 22.1^{\prime}$ & $146^{\circ} 57.1^{\prime}$ & 287.2 & 9.6 & 92 & 47140 \\
\hline 17 & 8 & 1973 & 0.0 & 342 & $41^{\circ} 21.4^{\prime}$ & $147^{\circ} 18.8^{\prime}$ & 303.5 & 9.6 & 93 & 47030 \\
\hline 17 & 8 & 1973 & 0.0 & 454 & $41^{\circ} 20.8^{\prime}$ & $147^{\circ} 34.1^{\prime}$ & 315.1 & 9.5 & 99 & 46952 \\
\hline 17 & 8 & 1973 & 0.0 & 500 & $41^{\circ} 20.7^{\prime}$ & $147^{\circ} 35.4^{\prime}$ & 316.0 & 8.5 & 101 & 46945 \\
\hline 17 & 8 & 1973 & 0.0 & 530 & $41^{\circ} 19.8^{\prime}$ & $147^{\circ} 40.9^{\prime}$ & 320.2 & 5.0 & 104 & 46911 \\
\hline 17 & 8 & 1973 & 0.0 & 532 & $41^{\circ} 19.8^{\prime}$ & $147^{\circ} 41.1^{\prime}$ & 320.4 & 5.3 & 97 & 46909 \\
\hline 17 & 8 & 1973 & 0.0 & 630 & $41^{\circ} 19.2^{\prime}$ & $147^{\circ} 47.9^{\prime}$ & 325.6 & 9.6 & 97 & 46871 \\
\hline 17 & 8 & 1973 & 0.0 & 1000 & $41^{\circ} 15.2^{\prime}$ & $148^{\circ} 32.3^{\prime}$ & 359.1 & 9.2 & 103 & 46625 \\
\hline 17 & 8 & 1973 & 0.0 & 1100 & $41^{\circ} 13.1^{\prime}$ & $148^{\circ} 44.2^{\prime}$ & 368.3 & 9.7 & 100 & 46550 \\
\hline 17 & 8 & 1973 & 0.0 & 1146 & $41^{\circ} 11.9^{\prime}$ & $148^{\circ} 53.9^{\prime}$ & 375.7 & 10.5 & 95 & 46493 \\
\hline 17 & 8 & 1973 & 0.0 & 1226 & $41^{\circ} 11.3^{\prime}$ & $149^{\circ} 3.1^{\prime}$ & 382.7 & 7.2 & 95 & 46444 \\
\hline 17 & 8 & 1973 & 0.0 & 1326 & $41^{\circ} 10.6^{\prime}$ & $149^{\circ} 12.6^{\prime}$ & 389.9 & 7.3 & 134 & 46394 \\
\hline 17 & 8 & 1973 & 0.0 & 1345 & $41^{\circ} 9.0^{\prime}$ & $149^{\circ} 14.8^{\prime}$ & 392.2 & 10.7 & 95 & 46368 \\
\hline 17 & 8 & 1973 & 0.0 & 1358 & $41^{\circ} 8.8^{\prime}$ & $149^{\circ} 17.9^{\prime}$ & 394.5 & 10.3 & 94 & 46352 \\
\hline 17 & 8 & 1973 & 0.0 & 1542 & $41^{\circ} 7.6^{\prime}$ & $149^{\circ} 41.6^{\prime}$ & 412.4 & 10.2 & 93 & 46233 \\
\hline 17 & 8 & 1973 & 0.0 & 1734 & $41^{\circ} \quad 6.6^{\prime}$ & $150^{\circ} 6.9^{\prime}$ & 431.5 & 10.6 & 96 & 46109 \\
\hline 17 & 8 & 1973 & 0.0 & 1834 & $41^{\circ} \quad 5.5^{\prime}$ & $150^{\circ} 20.9^{\prime}$ & 442.1 & 10.4 & 93 & 46036 \\
\hline 17 & 8 & 1973 & 0.0 & 2026 & $41^{\circ} \quad 4.4^{\prime}$ & $150^{\circ} 46.5^{\prime}$ & 461.4 & 10.4 & 98 & 45912 \\
\hline 17 & 8 & 1973 & 0.0 & 2120 & $41^{\circ} 3.1^{\prime}$ & $150^{\circ} 58.8^{\prime}$ & 470.8 & 10.0 & 90 & 45845 \\
\hline 17 & 8 & 1973 & 0.0 & 2256 & $41^{\circ} 3.1^{\prime}$ & $151^{\circ} 20.1^{\prime}$ & 486.9 & 10.7 & 93 & 45752 \\
\hline 18 & 8 & 1973 & 0.0 & 000 & $41^{\circ} \quad 2.5^{\prime}$ & $151^{\circ} 35.2^{\prime}$ & 498.2 & 10.6 & 93 & 45681 \\
\hline 18 & 8 & 1973 & 0.0 & 046 & $41^{\circ} 2.1^{\prime}$ & $151^{\circ} 45.9^{\prime}$ & 506.3 & 10.2 & 89 & 45630 \\
\hline 18 & 8 & 1973 & 0.0 & 254 & $41^{\circ} 2.4^{\prime}$ & $152^{\circ} 14.6^{\prime}$ & 528.0 & 10.3 & 94 & 45511 \\
\hline 18 & 8 & 1973 & 0.0 & 400 & $41^{\circ} 1.7^{\prime}$ & $152^{\circ} 29.6^{\prime}$ & 539.3 & 10.1 & 98 & 45440 \\
\hline 18 & 8 & 1973 & 0.0 & 442 & $41^{\circ} \quad 0.7^{\prime}$ & $152^{\circ} 38.9^{\prime}$ & 546.4 & 9.9 & 95 & 45392 \\
\hline 18 & 8 & 1973 & 0.0 & 546 & $40^{\circ} 59.7^{\prime}$ & $152^{\circ} 52.8^{\prime}$ & 556.9 & 10.3 & 99 & 45324 \\
\hline 18 & 8 & 1973 & 0.0 & 700 & $40^{\circ} 57.7^{\prime}$ & $153^{\circ} 9.4^{\prime}$ & 569.7 & 10.3 & 97 & 45236 \\
\hline 18 & 8 & 1973 & 0.0 & 730 & $40^{\circ} 57.1^{\prime}$ & $153^{\circ} 16.2^{\prime}$ & 574.8 & 9.7 & 100 & 45202 \\
\hline 18 & 8 & 1973 & 0.0 & 810 & $40^{\circ} 56.0^{\prime}$ & $153^{\circ} 24.6^{\prime}$ & 581.2 & 10.1 & 95 & 45157 \\
\hline 18 & 8 & 1973 & 0.0 & 922 & $40^{\circ} 54.9^{\prime}$ & $153^{\circ} 40.6^{\prime}$ & 593.4 & 10.4 & 94 & 45081 \\
\hline 18 & 8 & 1973 & 0.0 & 1056 & $40^{\circ} 53.7^{\prime}$ & $154^{\circ} 2.1^{\prime}$ & 609.7 & 10.6 & 92 & 44982 \\
\hline 18 & 8 & 1973 & 0.0 & 1228 & $40^{\circ} 53.1^{\prime}$ & $154^{\circ} 23.6^{\prime}$ & 626.0 & 10.4 & 170 & 44891 \\
\hline 18 & 8 & 1973 & 0.0 & 1232 & $40^{\circ} 52.4^{\prime}$ & $154^{\circ} 23.8^{\prime}$ & 626.7 & 5.4 & 170 & 44883 \\
\hline 18 & 8 & 1973 & 0.0 & 1318 & $40^{\circ} 48.4^{\prime}$ & $154^{\circ} 24.7^{\prime}$ & 630.8 & 0.0 & 97 & 44840 \\
\hline 23 & 8 & 1973 & 0.0 & 2216 & $40^{\circ} 48.1^{\prime}$ & $154^{\circ} 27.6^{\prime}$ & 633.0 & 10.7 & 165 & 44826 \\
\hline 23 & 8 & 1973 & 0.0 & 2324 & $40^{\circ} 36.4^{\prime}$ & $154^{\circ} 31.8^{\prime}$ & 645.1 & 10.6 & 165 & 44695 \\
\hline
\end{tabular}


TABLE 1 - Continued

\begin{tabular}{|c|c|c|c|c|c|c|c|c|c|c|}
\hline Day & Mon & Year & $\mathrm{TZ}$ & Time & Latitude & Longitude & Distance & Speed & Course & Regional Mag \\
\hline 24 & 8 & 1973 & 0.0 & 000 & $40^{\circ} 30.2^{\prime}$ & $154^{\circ} 34.0^{\prime}$ & 651.5 & 9.7 & 165 & 44627 \\
\hline 24 & 8 & 1973 & 0.0 & 136 & $40^{\circ} 15.2^{\prime}$ & $154^{\circ} 39.2^{\prime}$ & 667.1 & 9.8 & 167 & 44460 \\
\hline 24 & 8 & 1973 & 0.0 & 236 & $40^{\circ} 5.7^{\prime}$ & $154^{\circ} 42.2^{\prime}$ & 676.9 & 9.4 & 165 & 44356 \\
\hline 24 & 8 & 1973 & 0.0 & 324 & $39^{\circ} 58.4^{\prime}$ & $154^{\circ} 44.8^{\prime}$ & 684.4 & 9.7 & 158 & 44276 \\
\hline 24 & 8 & 1973 & 0.0 & 410 & $39^{\circ} 51.5^{\prime}$ & $154^{\circ} 48.4^{\prime}$ & 691.8 & 9.2 & 163 & 44195 \\
\hline 24 & 8 & 1973 & 0.0 & 510 & $39^{\circ} 42.7^{\prime}$ & $154^{\circ} 51.9^{\prime}$ & 701.0 & 9.1 & 158 & 44097 \\
\hline 24 & 8 & 1973 & 0.0 & 556 & $39^{\circ} 36.2^{\prime}$ & $154^{\circ} 55.3^{\prime}$ & 708.0 & 9.4 & 158 & 44021 \\
\hline 24 & 8 & 1973 & 0.0 & 746 & $39^{\circ} 20.3^{\prime}$ & $155^{\circ} 3.7^{\prime}$ & 725.3 & 0.0 & 74 & 43836 \\
\hline 27 & 8 & 1973 & 0.0 & 857 & $39^{\circ} 20.5^{\prime}$ & $155^{\circ} 4.8^{\prime}$ & 726.2 & 8.3 & 163 & 43834 \\
\hline 27 & 8 & 1973 & 0.0 & 1048 & $39^{\circ} 5.9^{\prime}$ & $155^{\circ} 10.6^{\prime}$ & 741.4 & 8.4 & 167 & 43672 \\
\hline 27 & 8 & 1973 & 0.0 & 1126 & $39^{\circ} 0.7^{\prime}$ & $155^{\circ} 12.1^{\prime}$ & 746.7 & 8.4 & 170 & 43617 \\
\hline 27 & 8 & 1973 & 0.0 & 1256 & $38^{\circ} 48.3^{\prime}$ & $155^{\circ} 15.0^{\prime}$ & 759.4 & 8.3 & 167 & 43488 \\
\hline 27 & 8 & 1973 & 0.0 & 1327 & $38^{\circ} 44.1^{\prime}$ & $155^{\circ} 16.3^{\prime}$ & 763.7 & 7.2 & 167 & 43444 \\
\hline 27 & 8 & 1973 & 0.0 & 1342 & $38^{\circ} 42.4^{\prime}$ & $155^{\circ} 16.8^{\prime}$ & 765.5 & 9.2 & 167 & 43425 \\
\hline 27 & 8 & 1973 & 0.0 & 1448 & $38^{\circ} 32.5^{\prime}$ & $155^{\circ} 19.8^{\prime}$ & 775.6 & 8.9 & 172 & 43321 \\
\hline 27 & 8 & 1973 & 0.0 & 1526 & $38^{\circ} 26.9^{\prime}$ & $155^{\circ} 20.8^{\prime}$ & 781.3 & 8.8 & 170 & 43264 \\
\hline 27 & 8 & 1973 & 0.0 & 1540 & $38^{\circ} 24.9^{\prime}$ & $155^{\circ} 21.3^{\prime}$ & 783.3 & 8.8 & 166 & 43243 \\
\hline 27 & 8 & 1973 & 0.0 & 1630 & $38^{\circ} 17.8^{\prime}$ & $155^{\circ} 23.6^{\prime}$ & 790.6 & 8.8 & 162 & 43168 \\
\hline 27 & 8 & 1973 & 0.0 & 1708 & $38^{\circ} 12.5^{\prime}$ & $155^{\circ} 25.8^{\prime}$ & 796.2 & 9.3 & 158 & 43110 \\
\hline 27 & 8 & 1973 & 0.0 & 2024 & $37^{\circ} 44.4^{\prime}$ & $155^{\circ} 40.1^{\prime}$ & 826.5 & 9.3 & 158 & 42794 \\
\hline 27 & 8 & 1973 & 0.0 & 2110 & $37^{\circ} 37.8^{\prime}$ & $155^{\circ} 43.5^{\prime}$ & 833.6 & 9.6 & 161 & 42720 \\
\hline 27 & 8 & 1973 & 0.0 & 2344 & $37^{\circ} 14.6^{\prime}$ & $155^{\circ} 53.8^{\prime}$ & 858.2 & 9.4 & 161 & 42469 \\
\hline 28 & 8 & 1973 & 0.0 & 000 & $37^{\circ} 12.2^{\prime}$ & $155^{\circ} 54.8^{\prime}$ & 860.7 & 9.7 & 162 & 42443 \\
\hline 28 & 8 & 1973 & 0.0 & 154 & $36^{\circ} 54.8^{\prime}$ & $156^{\circ} 2.1^{\prime}$ & 879.1 & 9.8 & 162 & 42258 \\
\hline 28 & 8 & 1973 & 0.0 & 235 & $36^{\circ} 48.4^{\prime}$ & $156^{\circ} 4.8^{\prime}$ & 885.8 & 10.0 & 167 & 42190 \\
\hline 28 & 8 & 1973 & 0.0 & 340 & $36^{\circ} 37.9^{\prime}$ & $156^{\circ} 7.9^{\prime}$ & 896.6 & 10.1 & 166 & 42083 \\
\hline 28 & 8 & 1973 & 0.0 & 606 & $36^{\circ} 14.1^{\prime}$ & $156^{\circ} 15.5^{\prime}$ & 921.2 & 10.1 & 171 & 41842 \\
\hline 28 & 8 & 1973 & 0.0 & 638 & $36^{\circ} 8.8^{\prime}$ & $156^{\circ} 16.6^{\prime}$ & 926.6 & 9.5 & 170 & 41790 \\
\hline 28 & 8 & 1973 & 0.0 & 800 & $35^{\circ} 55.9^{\prime}$ & $156^{\circ} 19.4^{\prime}$ & 939.6 & 9.0 & 165 & 41666 \\
\hline 28 & 8 & 1973 & 0.0 & 808 & $35^{\circ} 54.8^{\prime}$ & $156^{\circ} 19.8^{\prime}$ & 940.8 & 9.2 & 159 & 41654 \\
\hline 28 & 8 & 1973 & 0.0 & 1210 & $35^{\circ} 20.1^{\prime}$ & $156^{\circ} 36.4^{\prime}$ & 978.1 & 9.4 & 151 & 41291 \\
\hline 28 & 8 & 1973 & 0.0 & 1350 & $35^{\circ} \quad 6.5^{\prime}$ & $156^{\circ} 45.8^{\prime}$ & 993.7 & 9.4 & 153 & 41140 \\
\hline 28 & 8 & 1973 & 0.0 & 1425 & $35^{\circ} 1.6^{\prime}$ & $156^{\circ} 48.9^{\prime}$ & 999.2 & 9.4 & 162 & 41087 \\
\hline 28 & 8 & 1973 & 0.0 & 1536 & $34^{\circ} 51.0^{\prime}$ & $156^{\circ} 53.1^{\prime}$ & 1010.3 & 9.5 & 164 & 40981 \\
\hline 28 & 8 & 1973 & 0.0 & 1614 & $34^{\circ} 45.2^{\prime}$ & $156^{\circ} 55.1^{\prime}$ & 1016.4 & 9.6 & 172 & 40925 \\
\hline 28 & 8 & 1973 & 0.0 & 1724 & $34^{\circ} 34.1^{\prime}$ & $156^{\circ} 57.0^{\prime}$ & 1027.6 & 10.5 & 173 & 40823 \\
\hline 28 & 8 & 1973 & 0.0 & 1750 & $34^{\circ} 29.6^{\prime}$ & $156^{\circ} 57.7^{\prime}$ & 1032.1 & 9.8 & 172 & 40783 \\
\hline 28 & 8 & 1973 & 0.0 & 1930 & $34^{\circ} 13.5^{\prime}$ & $157^{\circ} 0.6^{\prime}$ & 1048.4 & 10.2 & 160 & 40637 \\
\hline 28 & 8 & 1973 & 0.0 & 1942 & $34^{\circ} 11.6^{\prime}$ & $157^{\circ} 1.4^{\prime}$ & 1050.4 & 9.7 & 159 & 40618 \\
\hline 28 & 8 & 1973 & 0.0 & 2108 & $33^{\circ} 58.6^{\prime}$ & $157^{\circ} 7.5^{\prime}$ & 1064.5 & 10.5 & 158 & 40488 \\
\hline 28 & 8 & 1973 & 0.0 & 2138 & $33^{\circ} 53.7^{\prime}$ & $157^{\circ} 9.9^{\prime}$ & 1069.6 & 10.8 & 165 & 40440 \\
\hline 28 & 8 & 1973 & 0.0 & 2250 & $33^{\circ} 41.2^{\prime}$ & $157^{\circ} 13.9^{\prime}$ & 1082.6 & 10.2 & 169 & 40322 \\
\hline 29 & 8 & 1973 & 0.0 & 000 & $33^{\circ} 29.5^{\prime}$ & $157^{\circ} 16.7^{\prime}$ & 1094.5 & 9.8 & 169 & 40217 \\
\hline 29 & 8 & 1973 & 0.0 & 438 & $32^{\circ} 44.9^{\prime}$ & $157^{\circ} 27.4^{\prime}$ & 1140.0 & 9.9 & 175 & 39820 \\
\hline 29 & 8 & 1973 & 0.0 & 514 & $32^{\circ} 39.0^{\prime}$ & $157^{\circ} 28.0^{\prime}$ & 1145.9 & 10.1 & 170 & 39771 \\
\hline 29 & 8 & 1973 & 0.0 & 520 & $32^{\circ} 38.0^{\prime}$ & $157^{\circ} 28.2^{\prime}$ & 1146.9 & 10.0 & 159 & 39762 \\
\hline 29 & 8 & 1973 & 0.0 & 550 & $32^{\circ} 33.3^{\prime}$ & $157^{\circ} 30.3^{\prime}$ & 1151.9 & 9.8 & 160 & 39718 \\
\hline 29 & 8 & 1973 & 0.0 & 732 & $32^{\circ} 17.6^{\prime}$ & $157^{\circ} 37.2^{\prime}$ & 1168.7 & 9.2 & 160 & 39572 \\
\hline 29 & 8 & 1973 & 0.0 & 800 & $32^{\circ} 13.5^{\prime}$ & $157^{\circ} 39.0^{\prime}$ & 1173.0 & 9.8 & 146 & 39535 \\
\hline 29 & 8 & 1973 & 0.0 & 906 & $32^{\circ} 4.6^{\prime}$ & $157^{\circ} 46.1^{\prime}$ & 1183.8 & 10.5 & 145 & 39443 \\
\hline 29 & 8 & 1973 & 0.0 & 1000 & $31^{\circ} 56.9^{\prime}$ & $157^{\circ} 52.5^{\prime}$ & 1193.3 & 9.3 & 325 & 39363 \\
\hline 29 & 8 & 1973 & 0.0 & 1020 & $31^{\circ} 59.4^{\prime}$ & $157^{\circ} 50.4^{\prime}$ & 1196.4 & 3.8 & 325 & 39389 \\
\hline 29 & 8 & 1973 & 0.0 & 1039 & $32^{\circ} 0.4^{\prime}$ & $157^{\circ} 49.6^{\prime}$ & 1197.6 & 0.0 & 112 & 39399 \\
\hline 3 & 9 & 1973 & 0.0 & 1015 & $31^{\circ} 59.9^{\prime}$ & $157^{\circ} 51.0^{\prime}$ & 1198.8 & 10.1 & 247 & 39392 \\
\hline 3 & 9 & 1973 & 0.0 & 1018 & $31^{\circ} 59.7^{\prime}$ & $157^{\circ} 50.4^{\prime}$ & 1199.3 & 9.4 & 280 & 39392 \\
\hline 3 & 9 & 1973 & 0.0 & 1032 & $32^{\circ} 0.1^{\prime}$ & $157^{\circ} 47.9^{\prime}$ & 1201.5 & 9.8 & 247 & 39402 \\
\hline 3 & 9 & 1973 & 0.0 & 1115 & $31^{\circ} 57.4^{\prime}$ & $157^{\circ} 40.3^{\prime}$ & 1208.5 & 9.8 & 238 & 39404 \\
\hline 3 & 9 & 1973 & 0.0 & 1240 & $31^{\circ} 50.0^{\prime}$ & $157^{\circ} 26.4^{\prime}$ & 1222.4 & 10.9 & 58 & 39389 \\
\hline 3 & 9 & 1973 & 0.0 & 1246 & $31^{\circ} 50.6^{\prime}$ & $157^{\circ} 27.5^{\prime}$ & 1223.5 & 4.7 & 0 & 39390 \\
\hline 3 & 9 & 1973 & 0.0 & 1313 & $31^{\circ} 52.7^{\prime}$ & $157^{\circ} 27.5^{\prime}$ & 1225.6 & 0.0 & 112 & 39407 \\
\hline 7 & 9 & 1973 & 0.0 & 2348 & $31^{\circ} 52.2^{\prime}$ & $157^{\circ} 28.7^{\prime}$ & 1226.7 & 10.5 & 137 & 39400 \\
\hline 8 & 9 & 1973 & 0.0 & 000 & $31^{\circ} 50.7^{\prime}$ & $157^{\circ} 30.4^{\prime}$ & 1228.8 & 9.4 & 137 & 39382 \\
\hline 8 & 9 & 1973 & 0.0 & 008 & $31^{\circ} 49.8^{\prime}$ & $157^{\circ} 31.4^{\prime}$ & 1230.0 & 9.0 & 138 & 39372 \\
\hline 8 & 9 & 1973 & 0.0 & 154 & $31^{\circ} 38.0^{\prime}$ & $157^{\circ} 43.9^{\prime}$ & 1245.9 & 9.5 & 136 & 39243 \\
\hline 8 & 9 & 1973 & 0.0 & 346 & $31^{\circ} 25.4^{\prime}$ & $157^{\circ} 58.4^{\prime}$ & 1263.6 & 9.0 & 138 & 39104 \\
\hline 8 & 9 & 1973 & 0.0 & 536 & $31^{\circ} 13.1^{\prime}$ & $158^{\circ} 11.4^{\prime}$ & 1280.2 & 9.2 & 136 & 38973 \\
\hline 8 & 9 & 1973 & 0.0 & 800 & $30^{\circ} 57.2^{\prime}$ & $158^{\circ} 29.4^{\prime}$ & 1302.3 & 9.7 & 135 & 38802 \\
\hline 8 & 9 & 1973 & 0.0 & 946 & $30^{\circ} 45.1^{\prime}$ & $158^{\circ} 43.5^{\prime}$ & 1319.4 & 9.5 & 139 & 38673 \\
\hline 8 & 9 & 1973 & 0.0 & 1204 & $30^{\circ} 28.7^{\prime}$ & $159^{\circ} \quad 0.2^{\prime}$ & 1341.2 & 9.8 & 137 & 38508 \\
\hline
\end{tabular}


TABLE 1 - Continued

\begin{tabular}{|c|c|c|c|c|c|c|c|c|c|c|}
\hline Day & Mon & Year & $\mathrm{TZ}$ & Time & Latitude & Longitude & Distance & Speed & Course & Regional Mag \\
\hline 8 & 9 & 1973 & 0.0 & 1350 & $30^{\circ} 16.1^{\prime}$ & $159^{\circ} 14.0^{\prime}$ & 1358.6 & 9.1 & 140 & 38380 \\
\hline 8 & 9 & 1973 & 0.0 & 1420 & $30^{\circ} 12.6^{\prime}$ & $159^{\circ} 17.4^{\prime}$ & 1363.1 & 9.7 & 135 & 38346 \\
\hline 8 & 9 & 1973 & 0.0 & 1540 & $30^{\circ} 8.4^{\prime}$ & $159^{\circ} 28.0^{\prime}$ & 1376.1 & 9.7 & 138 & 38252 \\
\hline 8 & 9 & 1973 & 0.0 & 1758 & $29^{\circ} 46.8^{\prime}$ & $159^{\circ} 45.2^{\prime}$ & 1398.4 & 9.3 & 137 & 38092 \\
\hline 8 & 9 & 1973 & 0.0 & 1916 & $29^{\circ} 37.9^{\prime}$ & $159^{\circ} 54.6^{\prime}$ & 1410.5 & 9.3 & 139 & 38006 \\
\hline 8 & 9 & 1973 & 0.0 & 2100 & $29^{\circ} 25.7^{\prime}$ & $160^{\circ} 6.7^{\prime}$ & 1426.6 & 9.2 & 137 & 37892 \\
\hline 8 & 9 & 1973 & 0.0 & 2326 & $29^{\circ} 9.4^{\prime}$ & $160^{\circ} 24.4^{\prime}$ & 1449.1 & 9.1 & 133 & 37739 \\
\hline 9 & 9 & 1973 & 0.0 & 000 & $29^{\circ} 5.8^{\prime}$ & $160^{\circ} 28.7^{\prime}$ & 1454.2 & 9.0 & 133 & 37705 \\
\hline 9 & 9 & 1973 & 0.0 & 136 & $28^{\circ} 55.9^{\prime}$ & $160^{\circ} 40.7^{\prime}$ & 1468.7 & 9.1 & 135 & 37610 \\
\hline 9 & 9 & 1973 & 0.0 & 256 & $28^{\circ} 47.3^{\prime}$ & $160^{\circ} 50.4^{\prime}$ & 1480.8 & 9.4 & 137 & 37531 \\
\hline 9 & 9 & 1973 & 0.0 & 417 & $28^{\circ} 38.1^{\prime}$ & $161^{\circ} 0.2^{\prime}$ & 1493.4 & 10.1 & 180 & 37448 \\
\hline 9 & 9 & 1973 & 0.0 & 420 & $28^{\circ} 37.6^{\prime}$ & $161^{\circ} 0.2^{\prime}$ & 1493.9 & 4.4 & 180 & 37445 \\
\hline 9 & 9 & 1973 & 0.0 & 509 & $28^{\circ} 33.9^{\prime}$ & $161^{\circ} 0.2^{\prime}$ & 1497.5 & 5.1 & 0 & 37422 \\
\hline 9 & 9 & 1973 & 0.0 & 530 & $28^{\circ} 35.7^{\prime}$ & $161^{\circ} 0.2^{\prime}$ & 1499.3 & 0.0 & 151 & 37433 \\
\hline 13 & 9 & 1973 & 0.0 & 729 & $28^{\circ} 34.5^{\prime}$ & $161^{\circ} 1.0^{\prime}$ & 1500.8 & 9.3 & 56 & 37423 \\
\hline 13 & 9 & 1973 & 0.0 & 1132 & $28^{\circ} 55.4^{\prime}$ & $161^{\circ} 36.6^{\prime}$ & 1538.4 & 9.3 & 56 & 37480 \\
\hline 13 & 9 & 1973 & 0.0 & 1215 & $28^{\circ} 59.1^{\prime}$ & $161^{\circ} 42.9^{\prime}$ & 1545.0 & 9.2 & 54 & 37490 \\
\hline 13 & 9 & 1973 & 0.0 & 1320 & $29^{\circ} 5.1^{\prime}$ & $161^{\circ} 52.0^{\prime}$ & 1555.0 & 8.9 & 54 & 37510 \\
\hline 13 & 9 & 1973 & 0.0 & 1458 & $29^{\circ} 13.7^{\prime}$ & $162^{\circ} 5.5^{\prime}$ & 1569.5 & 9.0 & 50 & 37538 \\
\hline 13 & 9 & 1973 & 0.0 & 1644 & $29^{\circ} 23.9^{\prime}$ & $162^{\circ} 19.5^{\prime}$ & 1585.5 & 9.0 & 52 & 37575 \\
\hline 13 & 9 & 1973 & 0.0 & 1724 & $29^{\circ} 27.6^{\prime}$ & $162^{\circ} 24.9^{\prime}$ & 1591.4 & 9.7 & 49 & 37589 \\
\hline 13 & 9 & 1973 & 0.0 & 1842 & $29^{\circ} 35.9^{\prime}$ & $162^{\circ} 35.9^{\prime}$ & 1604.1 & 9.3 & 49 & 37621 \\
\hline 13 & 9 & 1973 & 0.0 & 1930 & $29^{\circ} 40.8^{\prime}$ & $162^{\circ} 42.3^{\prime}$ & 1611.5 & 9.4 & 54 & 37641 \\
\hline 13 & 9 & 1973 & 0.0 & 2250 & $29^{\circ} 59.3^{\prime}$ & $163^{\circ} 11.4^{\prime}$ & 1642.8 & 9.4 & 55 & 37707 \\
\hline 14 & 9 & 1973 & 0.0 & 000 & $30^{\circ} 5.6^{\prime}$ & $163^{\circ} 21.8^{\prime}$ & 1653.8 & 9.7 & 55 & 37729 \\
\hline 14 & 9 & 1973 & 0.0 & 036 & $30^{\circ} 8.9^{\prime}$ & $163^{\circ} 27.3^{\prime}$ & 1659.6 & 9.3 & 57 & 37740 \\
\hline 14 & 9 & 1973 & 0.0 & 518 & $30^{\circ} 32.5^{\prime}$ & $164^{\circ} 9.8^{\prime}$ & 1703.2 & 9.4 & 58 & 37821 \\
\hline 14 & 9 & 1973 & 0.0 & 706 & $30^{\circ} 41.4^{\prime}$ & $164^{\circ} 26.5^{\prime}$ & 1720.1 & 8.7 & 57 & 37851 \\
\hline 14 & 9 & 1973 & 0.0 & 822 & $30^{\circ} 47.4^{\prime}$ & $164^{\circ} 37.3^{\prime}$ & 1731.2 & 9.4 & 58 & 37873 \\
\hline 14 & 9 & 1973 & 0.0 & 1046 & $30^{\circ} 59.4^{\prime}$ & $164^{\circ} 59.6^{\prime}$ & 1753.8 & 9.9 & 57 & 37917 \\
\hline 14 & 9 & 1973 & 0.0 & 1224 & $31^{\circ} 8.1^{\prime}$ & $165^{\circ} 15.4^{\prime}$ & 1769.8 & 9.9 & 59 & 37950 \\
\hline 14 & 9 & 1973 & 0.0 & 1406 & $31^{\circ} 16.9^{\prime}$ & $165^{\circ} 32.2^{\prime}$ & 1786.7 & 10.2 & 57 & 37984 \\
\hline 14 & 9 & 1973 & 0.0 & 1552 & $31^{\circ} 26.6^{\prime}$ & $165^{\circ} 50.0^{\prime}$ & 1804.7 & 10.3 & 59 & 38023 \\
\hline 14 & 9 & 1973 & 0.0 & 1940 & $31^{\circ} 46.5^{\prime}$ & $166^{\circ} 29.5^{\prime}$ & 1843.8 & 10.3 & 62 & 38101 \\
\hline 14 & 9 & 1973 & 0.0 & 2100 & $31^{\circ} 53.0^{\prime}$ & $166^{\circ} 43.7^{\prime}$ & 1857.5 & 11.2 & 59 & 38126 \\
\hline 14 & 9 & 1973 & 0.0 & 2126 & $31^{\circ} 55.5^{\prime}$ & $166^{\circ} 48.6^{\prime}$ & 1862.4 & 10.7 & 57 & 38137 \\
\hline 14 & 9 & 1973 & 0.0 & 2346 & $32^{\circ} 9.3^{\prime}$ & $167^{\circ} 13.3^{\prime}$ & 1887.4 & 10.7 & 53 & 38200 \\
\hline 15 & 9 & 1973 & 0.0 & 000 & $32^{\circ} 10.8^{\prime}$ & $167^{\circ} 15.6^{\prime}$ & 1889.9 & 10.1 & 53 & 38207 \\
\hline 15 & 9 & 1973 & 0.0 & 430 & $32^{\circ} 38.4^{\prime}$ & $167^{\circ} 58.6^{\prime}$ & 1935.5 & 9.8 & 55 & 38349 \\
\hline 15 & 9 & 1973 & 0.0 & 500 & $32^{\circ} 41.2^{\prime}$ & $168^{\circ} 3.4^{\prime}$ & 1940.4 & 9.7 & 56 & 38363 \\
\hline 15 & 9 & 1973 & 0.0 & 618 & $32^{\circ} 48.2^{\prime}$ & $168^{\circ} 15.9^{\prime}$ & 1953.0 & 10.2 & 60 & 38399 \\
\hline 15 & 9 & 1973 & 0.0 & 1142 & $33^{\circ} 15.5^{\prime}$ & $169^{\circ} 12.8^{\prime}$ & 2008.0 & 9.9 & 58 & 38532 \\
\hline 15 & 9 & 1973 & 0.0 & 1250 & $33^{\circ} 21.4^{\prime}$ & $169^{\circ} 24.2^{\prime}$ & 2019.2 & 10.2 & 92 & 38563 \\
\hline 15 & 9 & 1973 & 0.0 & 1300 & $33^{\circ} 21.3^{\prime}$ & $169^{\circ} 26.2^{\prime}$ & 2020.9 & 10.5 & 58 & 38560 \\
\hline 15 & 9 & 1973 & 0.0 & 1330 & $33^{\circ} 24.1^{\prime}$ & $169^{\circ} 31.5^{\prime}$ & 2026.1 & 10.8 & 54 & 38575 \\
\hline 15 & 9 & 1973 & 0.0 & 1645 & $33^{\circ} 44.9^{\prime}$ & $170^{\circ} 5.3^{\prime}$ & 2061.1 & 11.6 & 48 & 38695 \\
\hline 15 & 9 & 1973 & 0.0 & 1650 & $33^{\circ} 45.5^{\prime}$ & $170^{\circ} 6.2^{\prime}$ & 2062.1 & 11.6 & 44 & 38699 \\
\hline 15 & 9 & 1973 & 0.0 & 1900 & $34^{\circ} 3.5^{\prime}$ & $170^{\circ} 27.2^{\prime}$ & 2087.1 & 10.9 & 49 & 38815 \\
\hline 15 & 9 & 1973 & 0.0 & 1920 & $34^{\circ} 5.9^{\prime}$ & $170^{\circ} 30.5^{\prime}$ & 2090.8 & 11.2 & 54 & 38830 \\
\hline 15 & 9 & 1973 & 0.0 & 2038 & $34^{\circ} 14.4^{\prime}$ & $170^{\circ} 44.7^{\prime}$ & 2105.3 & 10.9 & 55 & 38882 \\
\hline 15 & 9 & 1973 & 0.0 & 2258 & $34^{\circ} 28.9^{\prime}$ & $171^{\circ} 10.0^{\prime}$ & 2130.7 & 10.9 & 64 & 38971 \\
\hline 16 & 9 & 1973 & 0.0 & 000 & $34^{\circ} 33.9^{\prime}$ & $171^{\circ} 22.3^{\prime}$ & 2142.0 & 10.6 & 64 & 39000 \\
\hline 16 & 9 & 1973 & 0.0 & 100 & $34^{\circ} 38.6^{\prime}$ & $171^{\circ} 33.9^{\prime}$ & 2152.6 & 11.0 & 69 & 39026 \\
\hline 16 & 9 & 1973 & 0.0 & 120 & $34^{\circ} 39.9^{\prime}$ & $171^{\circ} 38.0^{\prime}$ & 2156.3 & 10.3 & 66 & 39033 \\
\hline 16 & 9 & 1973 & 0.0 & 212 & $34^{\circ} 43.5^{\prime}$ & $171^{\circ} 47.9^{\prime}$ & 2165.2 & 10.0 & 59 & 39053 \\
\hline 16 & 9 & 1973 & 0.0 & 252 & $34^{\circ} 46.9^{\prime}$ & $171^{\circ} 54.8^{\prime}$ & 2171.8 & 9.2 & 48 & 39075 \\
\hline 16 & 9 & 1973 & 0.0 & 436 & $34^{\circ} 57.6^{\prime}$ & $172^{\circ} 9.2^{\prime}$ & 2187.7 & 5.6 & 0 & 39148 \\
\hline 16 & 9 & 1973 & 0.0 & 516 & $35^{\circ} 1.4^{\prime}$ & $172^{\circ} 9.2^{\prime}$ & 2191.5 & 7.5 & 267 & 39177 \\
\hline 16 & 9 & 1973 & 0.0 & 528 & $35^{\circ} \quad 1.3^{\prime}$ & $172^{\circ} 7.4^{\prime}$ & 2193.0 & 7.5 & 269 & 39178 \\
\hline 16 & 9 & 1973 & 0.0 & 545 & $35^{\circ} 1.3^{\prime}$ & $172^{\circ} 4.8^{\prime}$ & 2195.1 & 7.4 & 105 & 39180 \\
\hline 16 & 9 & 1973 & 0.0 & 612 & $35^{\circ} \quad 0.4^{\prime}$ & $172^{\circ} 8.7^{\prime}$ & 2198.4 & 4.5 & 106 & 39170 \\
\hline 16 & 9 & 1973 & 0.0 & 620 & $\begin{array}{ll}35^{\circ} & 0.2^{\prime}\end{array}$ & $172^{\circ} 9.4^{\prime}$ & 2199.0 & 0.1 & 186 & 39168 \\
\hline 17 & 9 & 1973 & 0.0 & 235 & $34^{\circ} 57.5^{\prime}$ & $172^{\circ} 9.1^{\prime}$ & 2201.7 & 8.9 & 360 & 39147 \\
\hline 17 & 9 & 1973 & 0.0 & 237 & $34^{\circ} 57.8^{\prime}$ & $172^{\circ} 9.1^{\prime}$ & 2202.0 & 8.3 & 259 & 39149 \\
\hline 17 & 9 & 1973 & 0.0 & 440 & $34^{\circ} 54.6^{\prime}$ & $171^{\circ} 48.7^{\prime}$ & 2219.0 & 8.2 & 261 & 39140 \\
\hline 17 & 9 & 1973 & 0.0 & 508 & $34^{\circ} 54.0^{\prime}$ & $171^{\circ} 44.1^{\prime}$ & 2222.9 & 7.7 & 283 & 39139 \\
\hline 17 & 9 & 1973 & 0.0 & 602 & $34^{\circ} 55.6^{\prime}$ & $171^{\circ} 35.9^{\prime}$ & 2229.8 & 6.9 & 275 & 39158 \\
\hline 17 & 9 & 1973 & 0.0 & 632 & $34^{\circ} 55.9^{\prime}$ & $171 \circ 31.7^{\prime}$ & 2233.2 & 7.6 & 282 & 39163 \\
\hline 17 & 9 & 1973 & 0.0 & 655 & $34^{\circ} 56.5^{\prime}$ & $171 \circ 28.2^{\prime}$ & 2236.1 & 8.1 & 105 & 39171 \\
\hline
\end{tabular}


TABLE 1 - Continued

\begin{tabular}{|c|c|c|c|c|c|c|c|c|c|c|}
\hline Day & Mon & Year & $\mathrm{TZ}$ & Time & Latitude & Longitude & Distance & Speed & Course & Regional Mag \\
\hline 17 & 9 & 1973 & 0.0 & 732 & $34^{\circ} 55.1^{\prime}$ & $171^{\circ} 34.1^{\prime}$ & 2241.2 & 0.1 & 156 & 39156 \\
\hline 18 & 9 & 1973 & 0.0 & 230 & $34^{\circ} 53.9^{\prime}$ & $171^{\circ} 34.8^{\prime}$ & 2242.5 & 4.2 & 66 & 39145 \\
\hline 18 & 9 & 1973 & 0.0 & 250 & $34^{\circ} 54.5^{\prime}$ & $171^{\circ} 36.4^{\prime}$ & 2243.9 & 10.1 & 65 & 39149 \\
\hline 18 & 9 & 1973 & 0.0 & 406 & $34^{\circ} 59.8^{\prime}$ & $171^{\circ} 50.5^{\prime}$ & 2256.6 & 9.6 & 70 & 39179 \\
\hline 18 & 9 & 1973 & 0.0 & 542 & $35^{\circ} 5.1^{\prime}$ & $172^{\circ} 8.2^{\prime}$ & 2272.1 & 10.3 & 74 & 39207 \\
\hline 18 & 9 & 1973 & 0.0 & 630 & $35^{\circ} 7.4^{\prime}$ & $172^{\circ} 17.8^{\prime}$ & 2280.3 & 9.5 & 72 & 39218 \\
\hline 18 & 9 & 1973 & 0.0 & 658 & $35^{\circ} 8.8^{\prime}$ & $172^{\circ} 23.0^{\prime}$ & 2284.7 & 9.3 & 61 & 39226 \\
\hline 18 & 9 & 1973 & 0.0 & 1102 & $35^{\circ} 27.2^{\prime}$ & $173^{\circ} 3.3^{\prime}$ & 2322.4 & 9.7 & 64 & 39346 \\
\hline 18 & 9 & 1973 & 0.0 & 1200 & $35^{\circ} 31.3^{\prime}$ & $173^{\circ} 13.7^{\prime}$ & 2331.8 & 9.6 & 68 & 39373 \\
\hline 18 & 9 & 1973 & 0.0 & 1216 & $35^{\circ} 32.3^{\prime}$ & $173^{\circ} 16.6^{\prime}$ & 2334.4 & 8.8 & 65 & 39379 \\
\hline 18 & 9 & 1973 & 0.0 & 1252 & $35^{\circ} 34.5^{\prime}$ & $173^{\circ} 22.5^{\prime}$ & 2339.7 & 9.4 & 69 & 39393 \\
\hline 18 & 9 & 1973 & 0.0 & 1402 & $35^{\circ} 38.5^{\prime}$ & $173^{\circ} 35.0^{\prime}$ & 2350.6 & 9.3 & 68 & 39419 \\
\hline 18 & 9 & 1973 & 0.0 & 1508 & $35^{\circ} 42.4^{\prime}$ & $173^{\circ} 46.6^{\prime}$ & 2360.8 & 8.9 & 67 & 39444 \\
\hline 18 & 9 & 1973 & 0.0 & 1602 & $35^{\circ} 45.6^{\prime}$ & $173^{\circ} 55.7^{\prime}$ & 2368.8 & 10.3 & 72 & 39465 \\
\hline 18 & 9 & 1973 & 0.0 & 1635 & $35^{\circ} 47.4^{\prime}$ & $174^{\circ} 2.3^{\prime}$ & 2374.5 & 9.8 & 70 & 39477 \\
\hline 18 & 9 & 1973 & 0.0 & 1656 & $35^{\circ} 48.5^{\prime}$ & $174^{\circ} 6.3^{\prime}$ & 2377.9 & 8.6 & 72 & 39484 \\
\hline 18 & 9 & 1973 & 0.0 & 1806 & $35^{\circ} 51.5^{\prime}$ & $174^{\circ} 18.1^{\prime}$ & 2387.9 & 8.2 & 69 & 39503 \\
\hline 18 & 9 & 1973 & 0.0 & 1840 & $35^{\circ} 53.2^{\prime}$ & $174^{\circ} 23.4^{\prime}$ & 2392.6 & 8.5 & 70 & 39515 \\
\hline 18 & 9 & 1973 & 0.0 & 2000 & $35^{\circ} 57.1^{\prime}$ & $174^{\circ} 36.5^{\prime}$ & 2403.9 & 8.4 & 63 & 39542 \\
\hline 18 & 9 & 1973 & 0.0 & 2045 & $35^{\circ} 59.9^{\prime}$ & $174^{\circ} 43.5^{\prime}$ & 2410.2 & 8.6 & 57 & 39562 \\
\hline 18 & 9 & 1973 & 0.0 & 2216 & $36^{\circ} 7.0^{\prime}$ & $174^{\circ} 57.1^{\prime}$ & 2423.3 & 9.0 & 52 & 39615 \\
\hline 18 & 9 & 1973 & 0.0 & 2328 & $36^{\circ} 13.6^{\prime}$ & $175^{\circ} 7.7^{\prime}$ & 2434.1 & 8.6 & 49 & 39665 \\
\hline 19 & 9 & 1973 & 0.0 & 000 & $36^{\circ} 16.6^{\prime}$ & $175^{\circ} 12.0^{\prime}$ & 2438.7 & 9.4 & 50 & 39688 \\
\hline 19 & 9 & 1973 & 0.0 & 004 & $36^{\circ} 17.0^{\prime}$ & $175^{\circ} 12.6^{\prime}$ & 2439.3 & 9.4 & 52 & 39691 \\
\hline 19 & 9 & 1973 & 0.0 & 050 & $36^{\circ} 21.5^{\prime}$ & $175^{\circ} 19.6^{\prime}$ & 2446.5 & 9.6 & 64 & 39726 \\
\hline 19 & 9 & 1973 & 0.0 & 114 & $36^{\circ} 23.2^{\prime}$ & $175^{\circ} 23.9^{\prime}$ & 2450.4 & 9.6 & 63 & 39739 \\
\hline 19 & 9 & 1973 & 0.0 & 314 & $36^{\circ} 32.0^{\prime}$ & $175^{\circ} 45.0^{\prime}$ & 2469.5 & 10.2 & 61 & 39806 \\
\hline 19 & 9 & 1973 & 0.0 & 450 & $36^{\circ} 40.0^{\prime}$ & $176^{\circ} 2.8^{\prime}$ & 2485.9 & 9.7 & 59 & 39869 \\
\hline 19 & 9 & 1973 & 0.0 & 530 & $36^{\circ} 43.4^{\prime}$ & $176^{\circ} 9.7^{\prime}$ & 2492.3 & 9.0 & 67 & 39896 \\
\hline 19 & 9 & 1973 & 0.0 & 642 & $36^{\circ} 47.5^{\prime}$ & $176^{\circ} 22.2^{\prime}$ & 2503.2 & 9.1 & 70 & 39929 \\
\hline 19 & 9 & 1973 & 0.0 & 754 & $36^{\circ} 51.2^{\prime}$ & $176^{\circ} 35.0^{\prime}$ & 2514.1 & 9.2 & 75 & 39958 \\
\hline 19 & 9 & 1973 & 0.0 & 822 & $36^{\circ} 52.3^{\prime}$ & $176^{\circ} 40.2^{\prime}$ & 2518.3 & 9.8 & 93 & 39967 \\
\hline 19 & 9 & 1973 & 0.0 & 930 & $36^{\circ} 51.7^{\prime}$ & $176^{\circ} 54.1^{\prime}$ & 2529.5 & 6.4 & 93 & 39962 \\
\hline 19 & 9 & 1973 & 0.0 & 955 & $36^{\circ} 51.6^{\prime}$ & $176^{\circ} 57.4^{\prime}$ & 2532.1 & 7.6 & 273 & 39961 \\
\hline 19 & 9 & 1973 & 0.0 & 1019 & $36^{\circ} 51.7^{\prime}$ & $176^{\circ} 53.6^{\prime}$ & 2535.2 & 0.1 & 259 & 39962 \\
\hline 24 & 9 & 1973 & 0.0 & 155 & $36^{\circ} 50.1$ & $176^{\circ} 43.1^{\prime}$ & 2543.7 & 3.6 & 151 & 39949 \\
\hline 24 & 9 & 1973 & 0.0 & 200 & $36^{\circ} 49.9^{\prime}$ & $176^{\circ} 43.3^{\prime}$ & 2544.0 & 5.7 & 151 & 39947 \\
\hline 24 & 9 & 1973 & 0.0 & 220 & $36^{\circ} 48.2^{\prime}$ & $176^{\circ} 44.5^{\prime}$ & 2545.9 & 9.5 & 150 & 39934 \\
\hline 24 & 9 & 1973 & 0.0 & 428 & $36^{\circ} 30.7^{\prime}$ & $176^{\circ} 56.9^{\prime}$ & 2566.0 & 8.9 & 149 & 39791 \\
\hline 24 & 9 & 1973 & 0.0 & 946 & $35^{\circ} 50.3^{\prime}$ & $177^{\circ} 26.7^{\prime}$ & 2613.0 & 9.2 & 145 & 39470 \\
\hline 24 & 9 & 1973 & 0.0 & 1130 & $35^{\circ} 37.2^{\prime}$ & $177^{\circ} 38.0^{\prime}$ & 2629.0 & 9.9 & 146 & 39369 \\
\hline 24 & 9 & 1973 & 0.0 & 1324 & $35^{\circ} 21.6^{\prime}$ & $177^{\circ} 51.0^{\prime}$ & 2647.9 & 10.7 & 143 & 39249 \\
\hline 24 & 9 & 1973 & 0.0 & 1424 & $35^{\circ} 13.1^{\prime}$ & $177^{\circ} 58.9^{\prime}$ & 2658.6 & 10.0 & 142 & 39185 \\
\hline 24 & 9 & 1973 & 0.0 & 1500 & $35^{\circ} 8.4^{\prime}$ & $178^{\circ} 3.4^{\prime}$ & 2664.6 & 10.8 & 147 & 39149 \\
\hline 24 & 9 & 1973 & 0.0 & 1536 & $35^{\circ} 2.9^{\prime}$ & $178^{\circ} 7.7^{\prime}$ & 2671.1 & 10.5 & 146 & 39108 \\
\hline 24 & 9 & 1973 & 0.0 & 1726 & $34^{\circ} 46.8^{\prime}$ & $178^{\circ} 20.7^{\prime}$ & 2690.4 & 10.4 & 147 & 38989 \\
\hline 24 & 9 & 1973 & 0.0 & 1836 & $34^{\circ} 36.7^{\prime}$ & $178^{\circ} 28.8^{\prime}$ & 2702.5 & 10.5 & 153 & 38915 \\
\hline 24 & 9 & 1973 & 0.0 & 1900 & $34^{\circ} 32.9^{\prime}$ & $178^{\circ} 31.1^{\prime}$ & 2706.7 & 10.2 & 155 & 38887 \\
\hline 24 & 9 & 1973 & 0.0 & 2318 & $33^{\circ} 53.0^{\prime}$ & $178^{\circ} 53.3^{\prime}$ & 2750.6 & 10.0 & 161 & 38598 \\
\hline 24 & 9 & 1973 & 0.0 & 2350 & $33^{\circ} 48.0^{\prime}$ & $178^{\circ} 55.4^{\prime}$ & 2755.9 & 8.6 & 152 & 38562 \\
\hline 25 & 9 & 1973 & 0.0 & 000 & $33^{\circ} 46.7^{\prime}$ & $178^{\circ} 56.2^{\prime}$ & 2757.4 & 9.2 & 152 & 38553 \\
\hline 25 & 9 & 1973 & 0.0 & 104 & $33^{\circ} 38.0^{\prime}$ & $179^{\circ} 1.7^{\prime}$ & 2767.2 & 9.3 & 150 & 38492 \\
\hline 25 & 9 & 1973 & 0.0 & 336 & $33^{\circ} 17.6^{\prime}$ & $179^{\circ} 15.6^{\prime}$ & 2790.7 & 9.7 & 148 & 38351 \\
\hline 25 & 9 & 1973 & 0.0 & 520 & $33^{\circ} 3.3^{\prime}$ & $179^{\circ} 26.3^{\prime}$ & 2807.6 & 9.5 & 147 & 38254 \\
\hline 25 & 9 & 1973 & 0.0 & 1040 & $32^{\circ} 20.8^{\prime}$ & $179^{\circ} 59.3^{\prime}$ & 2858.3 & 9.1 & 149 & 37974 \\
\hline 25 & 9 & 1973 & 0.0 & 1110 & $32^{\circ} 16.9^{\prime}$ & $-179^{\circ} 57.9^{\prime}$ & 2862.8 & 9.8 & 143 & 37949 \\
\hline 25 & 9 & 1973 & 0.0 & 1232 & $32^{\circ} 6.2^{\prime}$ & $-179^{\circ} 48.3^{\prime}$ & 2876.3 & 10.2 & 145 & 37881 \\
\hline 25 & 9 & 1973 & 0.0 & 1332 & $31^{\circ} 57.9^{\prime}$ & $-179^{\circ} 41.4^{\prime}$ & 2886.5 & 9.7 & 141 & 37829 \\
\hline 25 & 9 & 1973 & 0.0 & 1347 & $31^{\circ} 56.0^{\prime}$ & $-179^{\circ} 39.6^{\prime}$ & 2888.9 & 9.8 & 176 & 37817 \\
\hline 25 & 9 & 1973 & 0.0 & 1450 & $31^{\circ} 45.8^{\prime}$ & $-179^{\circ} 38.7^{\prime}$ & 2899.2 & 9.8 & 179 & 37749 \\
\hline 25 & 9 & 1973 & 0.0 & 1522 & $31^{\circ} 40.6^{\prime}$ & $-179^{\circ} 38.6^{\prime}$ & 2904.4 & 9.9 & 177 & 37714 \\
\hline 25 & 9 & 1973 & 0.0 & 1638 & $31^{\circ} 28.1^{\prime}$ & $-179^{\circ} 37.8^{\prime}$ & 2916.9 & 11.0 & 180 & 37631 \\
\hline 25 & 9 & 1973 & 0.0 & 1755 & $31^{\circ} 13.9^{\prime}$ & $-179^{\circ} 37.7^{\prime}$ & 2931.1 & 4.9 & 177 & 37538 \\
\hline 25 & 9 & 1973 & 0.0 & 1900 & $31^{\circ} 8.6^{\prime}$ & $-179^{\circ} 37.4^{\prime}$ & 2936.3 & 11.2 & 180 & 37503 \\
\hline 25 & 9 & 1973 & 0.0 & 1934 & $31^{\circ} \quad 2.3^{\prime}$ & $-179^{\circ} 37.4^{\prime}$ & 2942.7 & 10.6 & 180 & 37462 \\
\hline 25 & 9 & 1973 & 0.0 & 2158 & $30^{\circ} 36.9^{\prime}$ & $-179^{\circ} 37.5^{\prime}$ & 2968.1 & 10.4 & 181 & 37298 \\
\hline 26 & 9 & 1973 & 0.0 & 000 & $30^{\circ} 15.8^{\prime}$ & $-179^{\circ} 38.1^{\prime}$ & 2989.2 & 9.8 & 181 & 37164 \\
\hline 26 & 9 & 1973 & 0.0 & 234 & $29^{\circ} 50.6^{\prime}$ & $-179^{\circ} 38.7^{\prime}$ & 3014.4 & 9.9 & 179 & 37007 \\
\hline 26 & 9 & 1973 & 0.0 & 430 & $29^{\circ} 31.5^{\prime}$ & $-179^{\circ} 38.2^{\prime}$ & 3033.5 & 9.8 & 184 & 36890 \\
\hline
\end{tabular}


TABLE 1 - Continued

\begin{tabular}{|c|c|c|c|c|c|c|c|c|c|c|}
\hline Day & Mon & Year & $\mathrm{TZ}$ & Time & Latitude & Longitude & Distance & Speed & Course & Regional Mag \\
\hline 26 & 9 & 1973 & 0.0 & 500 & $29^{\circ} 26.6^{\prime}$ & $-179^{\circ} 38.6^{\prime}$ & 3038.4 & 9.5 & 185 & 36860 \\
\hline 26 & 9 & 1973 & 0.0 & 540 & $29^{\circ} 20.3^{\prime}$ & $-179^{\circ} 39.3^{\prime}$ & 3044.7 & 9.6 & 182 & 36822 \\
\hline 26 & 9 & 1973 & 0.0 & 855 & $28^{\circ} 49.3^{\prime}$ & $-179^{\circ} 40.8^{\prime}$ & 3075.8 & 9.6 & 219 & 36637 \\
\hline 26 & 9 & 1973 & 0.0 & 954 & $28^{\circ} 41.9^{\prime}$ & $-179^{\circ} 47.6^{\prime}$ & 3085.3 & 9.9 & 220 & 36589 \\
\hline 26 & 9 & 1973 & 0.0 & 1240 & $28^{\circ} 20.8^{\prime}$ & $179^{\circ} 52.5^{\prime}$ & 3112.7 & 9.1 & 220 & 36456 \\
\hline 26 & 9 & 1973 & 0.0 & 1307 & $28^{\circ} 17.6^{\prime}$ & $179^{\circ} 49.5^{\prime}$ & 3116.8 & 8.2 & 206 & 36436 \\
\hline 26 & 9 & 1973 & 0.0 & 1324 & $28^{\circ} 15.5^{\prime}$ & $179^{\circ} 48.4^{\prime}$ & 3119.1 & 9.1 & 199 & 36423 \\
\hline 26 & 9 & 1973 & 0.0 & 1350 & $28^{\circ} 11.8^{\prime}$ & $179^{\circ} 46.9^{\prime}$ & 3123.1 & 9.9 & 200 & 36401 \\
\hline 26 & 9 & 1973 & 0.0 & 1430 & $28^{\circ} 5.6^{\prime}$ & $179^{\circ} 44.3^{\prime}$ & 3129.7 & 9.7 & 200 & 36365 \\
\hline 26 & 9 & 1973 & 0.0 & 1444 & $28^{\circ} 3.5^{\prime}$ & $179^{\circ} 43.4^{\prime}$ & 3131.9 & 10.6 & 20 & 36353 \\
\hline 26 & 9 & 1973 & 0.0 & 1453 & $28^{\circ} 5.0^{\prime}$ & $179^{\circ} 44.0^{\prime}$ & 3133.5 & 4.9 & 20 & 36361 \\
\hline 26 & 9 & 1973 & 0.0 & 1525 & $28^{\circ} 7.4^{\prime}$ & $179^{\circ} 45.0^{\prime}$ & 3136.1 & 0.0 & 204 & 36376 \\
\hline 28 & 9 & 1973 & 0.0 & 1043 & $28^{\circ} 7.2^{\prime}$ & $179^{\circ} 44.9^{\prime}$ & 3136.4 & 6.3 & 143 & 36374 \\
\hline 28 & 9 & 1973 & 0.0 & 1106 & $28^{\circ} 5.3^{\prime}$ & $179^{\circ} 46.6^{\prime}$ & 3138.8 & 10.1 & 143 & 36364 \\
\hline 28 & 9 & 1973 & 0.0 & 1148 & $27^{\circ} 59.6^{\prime}$ & $179^{\circ} 51.4^{\prime}$ & 3145.9 & 10.0 & 139 & 36335 \\
\hline 28 & 9 & 1973 & 0.0 & 1246 & $27^{\circ} 52.3^{\prime}$ & $179^{\circ} 58.5^{\prime}$ & 3155.5 & 9.8 & 140 & 36299 \\
\hline 28 & 9 & 1973 & 0.0 & 1346 & $27^{\circ} 44.8^{\prime}$ & $-179^{\circ} 54.3^{\prime}$ & 3165.3 & 9.9 & 142 & 36261 \\
\hline 28 & 9 & 1973 & 0.0 & 1425 & $27^{\circ} 39.7^{\prime}$ & $-179^{\circ} 49.8^{\prime}$ & 3171.8 & 6.6 & 142 & 36236 \\
\hline 28 & 9 & 1973 & 0.0 & 1432 & $27^{\circ} 39.1^{\prime}$ & $-179^{\circ} 49.3^{\prime}$ & 3172.5 & 6.9 & 140 & 36233 \\
\hline 28 & 9 & 1973 & 0.0 & 1507 & $27^{\circ} 36.0^{\prime}$ & $-179^{\circ} 46.4^{\prime}$ & 3176.6 & 10.4 & 141 & 36218 \\
\hline 28 & 9 & 1973 & 0.0 & 1550 & $27^{\circ} 30.2^{\prime}$ & $-179^{\circ} 41.1^{\prime}$ & 3184.1 & 9.8 & 157 & 36189 \\
\hline 28 & 9 & 1973 & 0.0 & 1558 & $27^{\circ} 29.0^{\prime}$ & $-179^{\circ} 40.5^{\prime}$ & 3185.4 & 9.4 & 154 & 36183 \\
\hline 28 & 9 & 1973 & 0.0 & 1753 & $27^{\circ} 12.9^{\prime}$ & $-179 \circ 31.5^{\prime}$ & 3203.3 & 11.0 & 157 & 36102 \\
\hline 28 & 9 & 1973 & 0.0 & 1854 & $27^{\circ} 2.6^{\prime}$ & $-179^{\circ} 26.7^{\prime}$ & 3214.5 & 9.7 & 156 & 36050 \\
\hline 28 & 9 & 1973 & 0.0 & 2120 & $26^{\circ} 41.1^{\prime}$ & $-179^{\circ} 16.0^{\prime}$ & 3238.0 & 9.9 & 157 & 35944 \\
\hline 28 & 9 & 1973 & 0.0 & 2306 & $26^{\circ} 24.9^{\prime}$ & $-179^{\circ} 8.4^{\prime}$ & 3255.6 & 9.8 & 156 & 35865 \\
\hline 29 & 9 & 1973 & 0.0 & 000 & $26^{\circ} 16.8^{\prime}$ & $-179^{\circ} 4.4^{\prime}$ & 3264.4 & 10.1 & 156 & 35826 \\
\hline 29 & 9 & 1973 & 0.0 & 002 & $26^{\circ} 16.5^{\prime}$ & $-179^{\circ} \quad 4.3^{\prime}$ & 3264.7 & 10.2 & 159 & 35825 \\
\hline 29 & 9 & 1973 & 0.0 & 100 & $26^{\circ} 7.3^{\prime}$ & $-179^{\circ} \quad 0.3^{\prime}$ & 3274.6 & 10.2 & 163 & 35781 \\
\hline 29 & 9 & 1973 & 0.0 & 148 & $25^{\circ} 59.5^{\prime}$ & $-178^{\circ} 57.6^{\prime}$ & 3282.8 & 10.0 & 161 & 35744 \\
\hline 29 & 9 & 1973 & 0.0 & 202 & $25^{\circ} 57.3^{\prime}$ & $-178^{\circ} 56.8^{\prime}$ & 3285.1 & 9.2 & 69 & 35733 \\
\hline 29 & 9 & 1973 & 0.0 & 500 & $26^{\circ} 7.1^{\prime}$ & $-178^{\circ} 28.4^{\prime}$ & 3312.4 & 9.8 & 69 & 35803 \\
\hline 29 & 9 & 1973 & 0.0 & 620 & $26^{\circ} 11.7^{\prime}$ & $-178^{\circ} 14.8^{\prime}$ & 3325.5 & 9.1 & 157 & 35837 \\
\hline 29 & 9 & 1973 & 0.0 & 912 & $25^{\circ} 47.8^{\prime}$ & $-178^{\circ} 3.3^{\prime}$ & 3351.6 & 8.8 & 157 & 35725 \\
\hline 29 & 9 & 1973 & 0.0 & 1102 & $25^{\circ} 32.9^{\prime}$ & $-177^{\circ} 56.4^{\prime}$ & 3367.7 & 9.2 & 151 & 35657 \\
\hline 29 & 9 & 1973 & 0.0 & 1115 & $25^{\circ} 31.1^{\prime}$ & $-177^{\circ} 55.3^{\prime}$ & 3369.7 & 8.7 & 162 & 35649 \\
\hline 29 & 9 & 1973 & 0.0 & 1248 & $25^{\circ} 18.3^{\prime}$ & $-177^{\circ} 50.8^{\prime}$ & 3383.2 & 8.9 & 166 & 35591 \\
\hline 29 & 9 & 1973 & 0.0 & 1332 & $25^{\circ} 12.0^{\prime}$ & $-177^{\circ} 49.1^{\prime}$ & 3389.7 & 9.1 & 247 & 35562 \\
\hline 29 & 9 & 1973 & 0.0 & 1340 & $25^{\circ} 11.5^{\prime}$ & $-177^{\circ} 50.3^{\prime}$ & 3390.9 & 9.2 & 247 & 35558 \\
\hline 29 & 9 & 1973 & 0.0 & 1436 & $25^{\circ} 8.1^{\prime}$ & $-177^{\circ} 59.0^{\prime}$ & 3399.5 & 8.8 & 343 & 35535 \\
\hline 29 & 9 & 1973 & 0.0 & 1512 & $25^{\circ} 13.2^{\prime}$ & $-178^{\circ} \quad 0.7^{\prime}$ & 3404.8 & 8.7 & 340 & 35558 \\
\hline 29 & 9 & 1973 & 0.0 & 1810 & $25^{\circ} 37.4^{\prime}$ & $-178^{\circ} 10.3^{\prime}$ & 3430.5 & 9.0 & 341 & 35668 \\
\hline 29 & 9 & 1973 & 0.0 & 1818 & $25^{\circ} 38.5^{\prime}$ & $-178^{\circ} 10.7^{\prime}$ & 3431.7 & 6.2 & 161 & 35674 \\
\hline 29 & 9 & 1973 & 0.0 & 1945 & $25^{\circ} 30.1^{\prime}$ & $-178^{\circ} \quad 7.5^{\prime}$ & 3440.6 & 7.8 & 341 & 35635 \\
\hline 29 & 9 & 1973 & 0.0 & 2010 & $25^{\circ} 33.2^{\prime}$ & $-178^{\circ} 8.6^{\prime}$ & 3443.9 & 5.6 & 341 & 35649 \\
\hline 29 & 9 & 1973 & 0.0 & 2022 & $25^{\circ} 34.2^{\prime}$ & $-178^{\circ} \quad 9.0^{\prime}$ & 3445.0 & 0.1 & 354 & 35654 \\
\hline 1 & 10 & 1973 & 0.0 & 145 & $25^{\circ} 37.4^{\prime}$ & $-178^{\circ} 9.4^{\prime}$ & 3448.2 & 1.1 & 127 & 35669 \\
\hline 1 & 10 & 1973 & 0.0 & 155 & $25^{\circ} 37.3^{\prime}$ & $-178^{\circ} 9.2^{\prime}$ & 3448.3 & 8.4 & 131 & 35669 \\
\hline 1 & 10 & 1973 & 0.0 & 400 & $25^{\circ} 25.9^{\prime}$ & $-177^{\circ} 54.5^{\prime}$ & 3465.8 & 8.0 & 132 & 35625 \\
\hline 1 & 10 & 1973 & 0.0 & 512 & $25^{\circ} 19.5^{\prime}$ & $-177^{\circ} 46.6^{\prime}$ & 3475.4 & 8.7 & 128 & 35600 \\
\hline 1 & 10 & 1973 & 0.0 & 922 & $24^{\circ} 57.2^{\prime}$ & $-177^{\circ} 15.3^{\prime}$ & 3511.5 & 8.8 & 130 & 35517 \\
\hline 1 & 10 & 1973 & 0.0 & 1106 & $24^{\circ} 47.3^{\prime}$ & $-177^{\circ} 2.5^{\prime}$ & 3526.7 & 9.0 & 131 & 35483 \\
\hline 1 & 10 & 1973 & 0.0 & 1156 & $24^{\circ} 42.4^{\prime}$ & $-176^{\circ} 56.3^{\prime}$ & 3534.2 & 8.8 & 132 & 35465 \\
\hline 1 & 10 & 1973 & 0.0 & 1246 & $24^{\circ} 37.5^{\prime}$ & $-176^{\circ} 50.3^{\prime}$ & 3541.5 & 9.3 & 127 & 35448 \\
\hline 1 & 10 & 1973 & 0.0 & 1336 & $24^{\circ} 32.8^{\prime}$ & $-176^{\circ} 43.5^{\prime}$ & 3549.3 & 9.0 & 131 & 35432 \\
\hline 1 & 10 & 1973 & 0.0 & 1410 & $24^{\circ} 29.5^{\prime}$ & $-176^{\circ} 39.3^{\prime}$ & 3554.4 & 9.8 & 129 & 35420 \\
\hline 1 & 10 & 1973 & 0.0 & 1524 & $24^{\circ} 21.9^{\prime}$ & $-176^{\circ} 28.9^{\prime}$ & 3566.5 & 9.0 & 131 & 35394 \\
\hline 1 & 10 & 1973 & 0.0 & 1710 & $24^{\circ} 11.6^{\prime}$ & $-176^{\circ} 15.7^{\prime}$ & 3582.3 & 9.7 & 130 & 35359 \\
\hline 1 & 10 & 1973 & 0.0 & 1800 & $24^{\circ} \quad 6.4^{\prime}$ & $-176^{\circ} 9.0^{\prime}$ & 3590.4 & 9.4 & 129 & 35342 \\
\hline 1 & 10 & 1973 & 0.0 & 1814 & $24^{\circ} 5.0^{\prime}$ & $-176^{\circ} 7.1^{\prime}$ & 3592.6 & 9.0 & 128 & 35337 \\
\hline 1 & 10 & 1973 & 0.0 & 2040 & $23^{\circ} 51.6^{\prime}$ & $-175^{\circ} 48.0^{\prime}$ & 3614.6 & 9.2 & 125 & 36295 \\
\hline 1 & 10 & 1973 & 0.0 & 2214 & $23^{\circ} 43.3^{\prime}$ & $-175^{\circ} 35.2^{\prime}$ & 3628.9 & 8.8 & 126 & 35270 \\
\hline 2 & 10 & 1973 & 0.0 & 000 & $23^{\circ} 34.2^{\prime}$ & $-175^{\circ} 21.6^{\prime}$ & 3644.4 & 8.9 & 126 & 35242 \\
\hline 2 & 10 & 1973 & 0.0 & 002 & $23^{\circ} 34.0^{\prime}$ & $-175^{\circ} 21.3^{\prime}$ & 3644.7 & 9.1 & 129 & 35242 \\
\hline 2 & 10 & 1973 & 0.0 & 1016 & $22^{\circ} 35.9^{\prime}$ & $-174^{\circ} \quad 2.9^{\prime}$ & 3737.3 & 9.0 & 128 & 35070 \\
\hline 2 & 10 & 1973 & 0.0 & 1146 & $22^{\circ} 27.6^{\prime}$ & $-173^{\circ} 51.3^{\prime}$ & 3750.9 & 9.1 & 126 & 35047 \\
\hline 2 & 10 & 1973 & 0.0 & 1248 & $22^{\circ} 22.1^{\prime}$ & $-173^{\circ} 43.1^{\prime}$ & 3760.2 & 8.8 & 126 & 35033 \\
\hline 2 & 10 & 1973 & 0.0 & 1434 & $22^{\circ} 12.9^{\prime}$ & $-173^{\circ} 29.5^{\prime}$ & 3775.8 & 8.9 & 127 & 35009 \\
\hline 2 & 10 & 1973 & 0.0 & 1622 & $22^{\circ} 3.3^{\prime}$ & $-173^{\circ} 15.7^{\prime}$ & 3791.8 & 9.4 & 127 & 34984 \\
\hline
\end{tabular}


TABLE 1 - Continued

\begin{tabular}{|c|c|c|c|c|c|c|c|c|c|c|}
\hline Day & Mon & Year & $\mathrm{TZ}$ & Time & Latitude & Longitude & Distance & Speed & Course & Regional Mag \\
\hline 2 & 10 & 1973 & 0.0 & 1730 & $21^{\circ} 56.9^{\prime}$ & $-173^{\circ} 6.5^{\prime}$ & 3802.5 & 9.4 & 128 & 34967 \\
\hline 2 & 10 & 1973 & 0.0 & 2140 & $21^{\circ} 33.0^{\prime}$ & $-172^{\circ} 33.1^{\prime}$ & 3841.6 & 9.2 & 129 & 34906 \\
\hline 3 & 10 & 1973 & 0.0 & 000 & $21^{\circ} 19.3^{\prime}$ & $-172^{\circ} 15.2^{\prime}$ & 3863.2 & 9.6 & 129 & 34871 \\
\hline 3 & 10 & 1973 & 0.0 & 410 & $20^{\circ} 54.1^{\prime}$ & $-171^{\circ} 42.1^{\prime}$ & 3903.1 & 9.5 & 126 & 34808 \\
\hline 3 & 10 & 1973 & 0.0 & 514 & $20^{\circ} 48.1^{\prime}$ & $-171^{\circ} 33.3^{\prime}$ & 3913.2 & 9.4 & 127 & 34794 \\
\hline 3 & 10 & 1973 & 0.0 & 530 & $20^{\circ} 46.6^{\prime}$ & $-171^{\circ} 31.1^{\prime}$ & 3915.7 & 9.1 & 135 & 34790 \\
\hline 3 & 10 & 1973 & 0.0 & 746 & $20^{\circ} 32.1^{\prime}$ & $-171^{\circ} 15.5^{\prime}$ & 3936.3 & 9.4 & 132 & 34752 \\
\hline 3 & 10 & 1973 & 0.0 & 815 & $20^{\circ} 29.1^{\prime}$ & $-171^{\circ} 11.9^{\prime}$ & 3940.9 & 9.5 & 142 & 34744 \\
\hline 3 & 10 & 1973 & 0.0 & 1050 & $20^{\circ} 9.7^{\prime}$ & $-170^{\circ} 56.0^{\prime}$ & 3965.3 & 9.3 & 146 & 34688 \\
\hline 3 & 10 & 1973 & 0.0 & 1109 & $20^{\circ} 7.3^{\prime}$ & $-170^{\circ} 54.2^{\prime}$ & 3968.3 & 12.0 & 326 & 34681 \\
\hline 3 & 10 & 1973 & 0.0 & 1124 & $20^{\circ} 9.7^{\prime}$ & $-170^{\circ} 56.0^{\prime}$ & 3971.3 & 7.3 & 326 & 34688 \\
\hline 3 & 10 & 1973 & 0.0 & 1133 & $20^{\circ} 10.7^{\prime}$ & $-170^{\circ} 56.7^{\prime}$ & 3972.4 & 0.0 & 335 & 34691 \\
\hline 7 & 10 & 1973 & 0.0 & 535 & $20^{\circ} 11.6^{\prime}$ & $-170^{\circ} 57.2^{\prime}$ & 3973.4 & 9.0 & 90 & 34694 \\
\hline 7 & 10 & 1973 & 0.0 & 541 & $20^{\circ} 11.6^{\prime}$ & $-170^{\circ} 56.2^{\prime}$ & 3974.3 & 9.3 & 85 & 34695 \\
\hline 7 & 10 & 1973 & 0.0 & 800 & $20^{\circ} 13.5^{\prime}$ & $-170^{\circ} 33.4^{\prime}$ & 3995.8 & 9.2 & 83 & 34726 \\
\hline 7 & 10 & 1973 & 0.0 & 946 & $20^{\circ} 15.5^{\prime}$ & $-170^{\circ} 16.2^{\prime}$ & 4012.1 & 9.3 & 83 & 34753 \\
\hline 7 & 10 & 1973 & 0.0 & 1044 & $20^{\circ} 16.6^{\prime}$ & $-170^{\circ} \quad 6.7^{\prime}$ & 4021.0 & 9.4 & 82 & 34767 \\
\hline 7 & 10 & 1973 & 0.0 & 1144 & $20^{\circ} 17.8^{\prime}$ & $-169^{\circ} 56.8^{\prime}$ & 4030.4 & 9.1 & 83 & 34783 \\
\hline 7 & 10 & 1973 & 0.0 & 1204 & $20^{\circ} 18.2^{\prime}$ & $-169^{\circ} 53.6^{\prime}$ & 4033.4 & 9.0 & 82 & 34788 \\
\hline 7 & 10 & 1973 & 0.0 & 1654 & $20^{\circ} 23.9^{\prime}$ & $-169^{\circ} 7.5^{\prime}$ & 4077.0 & 9.1 & 86 & 34863 \\
\hline 7 & 10 & 1973 & 0.0 & 1730 & $20^{\circ} 24.3^{\prime}$ & $-169^{\circ} 1.7^{\prime}$ & 4082.5 & 8.7 & 89 & 34871 \\
\hline 7 & 10 & 1973 & 0.0 & 2110 & $20^{\circ} 24.7^{\prime}$ & $-168^{\circ} 27.6^{\prime}$ & 4114.4 & 8.1 & 88 & 34913 \\
\hline 7 & 10 & 1073 & 0.0 & 2204 & $20^{\circ} 25.0^{\prime}$ & $-168^{\circ} 19.8^{\prime}$ & 4121.8 & 8.6 & 89 & 34923 \\
\hline 7 & 10 & 1973 & 0.0 & 2328 & $20^{\circ} 25.2^{\prime}$ & $-168^{\circ} 7.0^{\prime}$ & 4133.8 & 8.7 & 87 & 34940 \\
\hline 8 & 10 & 1973 & 0.0 & 000 & $20^{\circ} 25.5^{\prime}$ & $-168^{\circ} 2.0^{\prime}$ & 4138.4 & 8.5 & 87 & 34947 \\
\hline 8 & 10 & 1973 & 0.0 & 028 & $20^{\circ} 25.7^{\prime}$ & $-167^{\circ} 57.8^{\prime}$ & 4142.4 & 8.3 & 83 & 34953 \\
\hline 8 & 10 & 1973 & 0.0 & 342 & $20^{\circ} 29.2^{\prime}$ & $-167^{\circ} 29.3^{\prime}$ & 4169.3 & 9.2 & 84 & 35003 \\
\hline 8 & 10 & 1973 & 0.0 & 436 & $20^{\circ} 30.0^{\prime}$ & $-167^{\circ} 20.5^{\prime}$ & 4177.6 & 8.0 & 81 & 35017 \\
\hline 8 & 10 & 1973 & 0.0 & 858 & $20^{\circ} 35.3^{\prime}$ & $-166^{\circ} 43.8^{\prime}$ & 4212.4 & 7.6 & 81 & 35086 \\
\hline 8 & 10 & 1973 & 0.0 & 952 & $20^{\circ} 36.4^{\prime}$ & $-166^{\circ} 36.6^{\prime}$ & 4219.2 & 8.1 & 83 & 35100 \\
\hline 8 & 10 & 1973 & 0.0 & 1025 & $20^{\circ} 36.9^{\prime}$ & $-166^{\circ} 31.9^{\prime}$ & 4223.6 & 8.1 & 87 & 35108 \\
\hline 8 & 10 & 1973 & 0.0 & 1114 & $20^{\circ} 37.2^{\prime}$ & $-166^{\circ} 24.8^{\prime}$ & 4230.3 & 8.2 & 90 & 35119 \\
\hline 8 & 10 & 1973 & 0.0 & 1318 & $20^{\circ} 37.3^{\prime}$ & $-166^{\circ} 6.6^{\prime}$ & 4247.3 & 8.6 & 91 & 35144 \\
\hline 8 & 10 & 1973 & 0.0 & 1645 & $20^{\circ} 36.7^{\prime}$ & $-165^{\circ} 34.8^{\prime}$ & 4277.0 & 8.0 & 88 & 35184 \\
\hline 8 & 10 & 1973 & 0.0 & 1838 & $20^{\circ} 37.1^{\prime}$ & $-165^{\circ} 18.8^{\prime}$ & 4292.1 & 7.6 & 85 & 35208 \\
\hline 8 & 10 & 1973 & 0.0 & 2110 & $20^{\circ} 38.8^{\prime}$ & $-164^{\circ} 58.4^{\prime}$ & 4311.2 & 7.3 & 87 & 35243 \\
\hline 8 & 10 & 1973 & 0.0 & 2234 & $20^{\circ} 39.3^{\prime}$ & $-164^{\circ} 47.5^{\prime}$ & 4321.4 & 7.3 & 86 & 35261 \\
\hline 9 & 10 & 1973 & 0.0 & 000 & $20^{\circ} 39.9^{\prime}$ & $-164^{\circ} 36.3^{\prime}$ & 4331.9 & 7.0 & 86 & 35279 \\
\hline 9 & 10 & 1973 & 0.0 & 022 & $20^{\circ} 40.1^{\prime}$ & $-164^{\circ} 33.6^{\prime}$ & 4334.5 & 7.3 & 86 & 35284 \\
\hline 9 & 10 & 1973 & 0.0 & 106 & $20^{\circ} 40.5^{\prime}$ & $-164^{\circ} 27.9^{\prime}$ & 4339.8 & 7.3 & 84 & 35293 \\
\hline 9 & 10 & 1973 & 0.0 & 250 & $20^{\circ} 41.8^{\prime}$ & $-164^{\circ} 14.5^{\prime}$ & 4352.4 & 7.2 & 80 & 35318 \\
\hline 9 & 10 & 1973 & 0.0 & 354 & $20^{\circ} 43.1^{\prime}$ & $-164^{\circ} 6.4^{\prime}$ & 4360.1 & 7.4 & 80 & 35336 \\
\hline 9 & 10 & 1973 & 0.0 & 810 & $20^{\circ} 48.8^{\prime}$ & $-163^{\circ} 33.1^{\prime}$ & 4391.8 & 7.8 & 78 & 35410 \\
\hline 9 & 10 & 1973 & 0.0 & 856 & $20^{\circ} 50.0^{\prime}$ & $-163^{\circ} 26.8^{\prime}$ & 4397.8 & 7.4 & 80 & 35425 \\
\hline 9 & 10 & 1973 & 0.0 & 930 & $20^{\circ} 50.8^{\prime}$ & $-163^{\circ} 22.4^{\prime}$ & 4401.9 & 7.7 & 83 & 35435 \\
\hline 9 & 10 & 1973 & 0.0 & 958 & $20^{\circ} 51.2^{\prime}$ & $-163^{\circ} 18.6^{\prime}$ & 4405.5 & 7.5 & 86 & 35442 \\
\hline 9 & 10 & 1973 & 0.0 & 1022 & $20^{\circ} 51.4^{\prime}$ & $-163^{\circ} 15.4^{\prime}$ & 4408.5 & 7.7 & 84 & 35448 \\
\hline 9 & 10 & 1973 & 0.0 & 1208 & $20^{\circ} 52.9^{\prime}$ & $-163^{\circ} 0.9^{\prime}$ & 4422.2 & 7.6 & 83 & 35477 \\
\hline 9 & 10 & 1973 & 0.0 & 1424 & $20^{\circ} 55.0^{\prime}$ & $-162^{\circ} 42.5^{\prime}$ & 4439.5 & 8.0 & 88 & 35514 \\
\hline 9 & 10 & 1973 & 0.0 & 2118 & $20^{\circ} 57.4^{\prime}$ & $-161^{\circ} 43.1^{\prime}$ & 4495.0 & & & 35618 \\
\hline
\end{tabular}

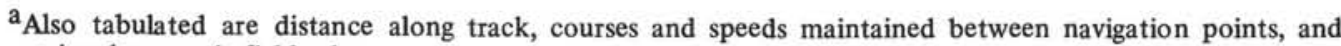
regional magnetic field values. 


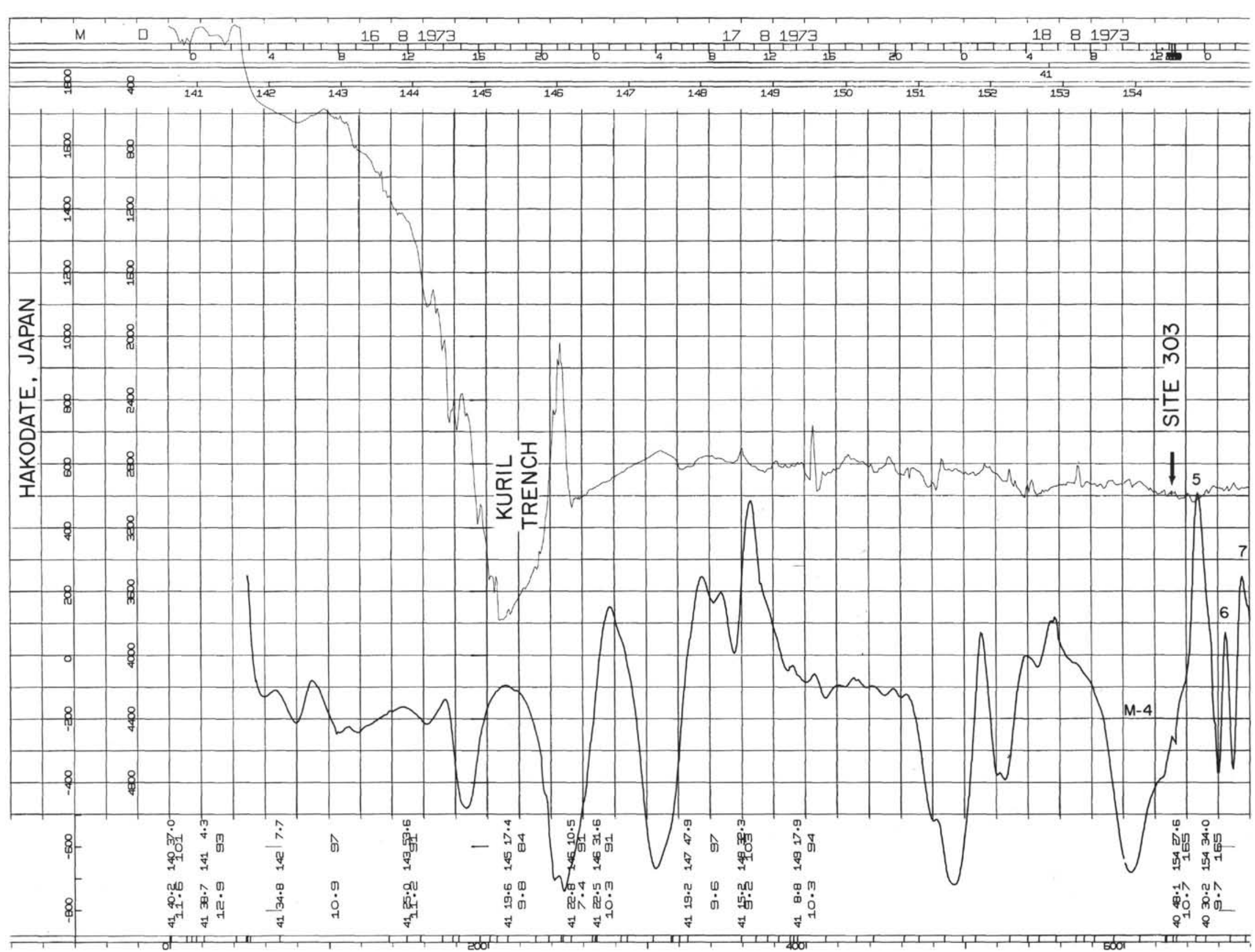



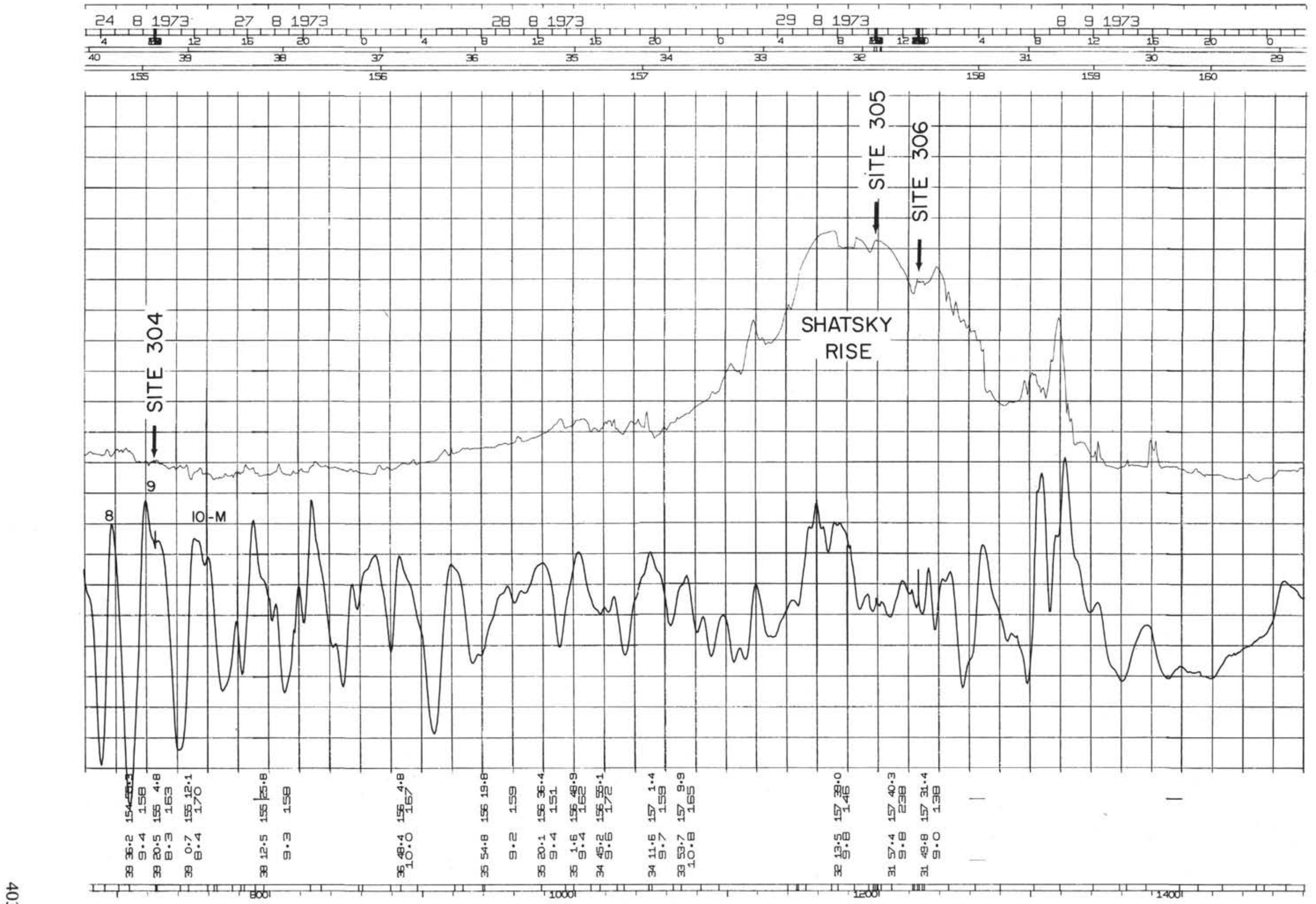

Figure 3. Magnetic anomaly and bathymetric profiles along the track of Leg 32 of Glomar Challenger. Plots and scales explained in text. 


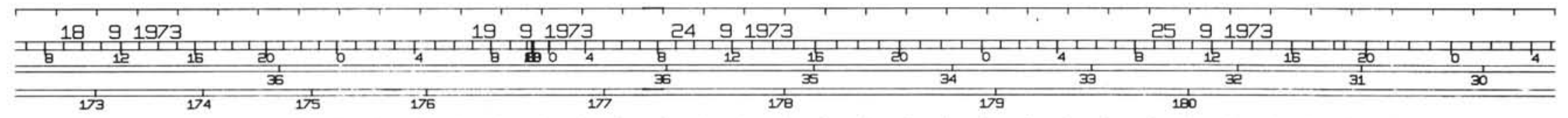

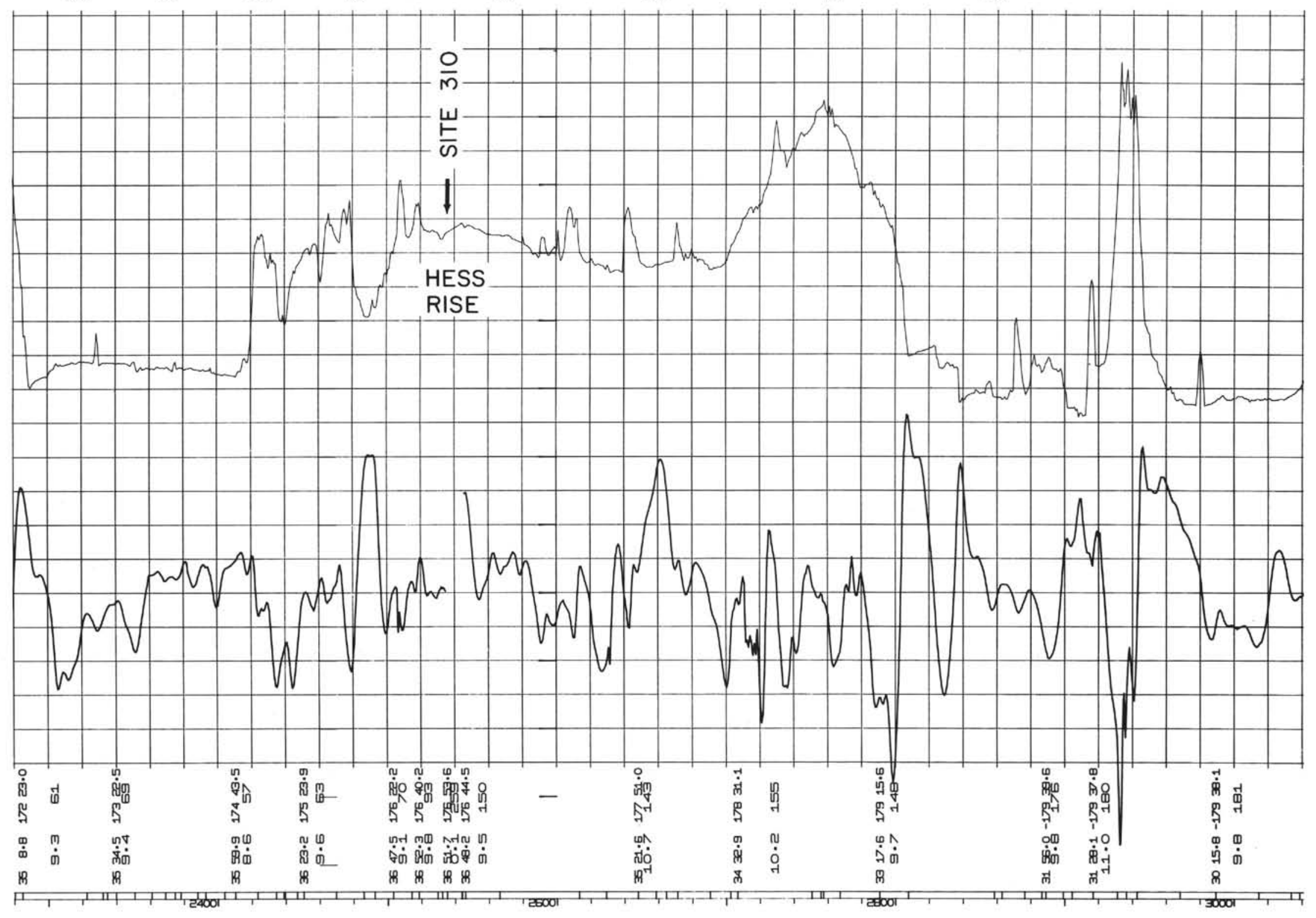

Figure 5. Magnetic anomaly and bathymetric profiles along the track of Leg 32 of Glomar Challenger. Plots and scales explained in text. 


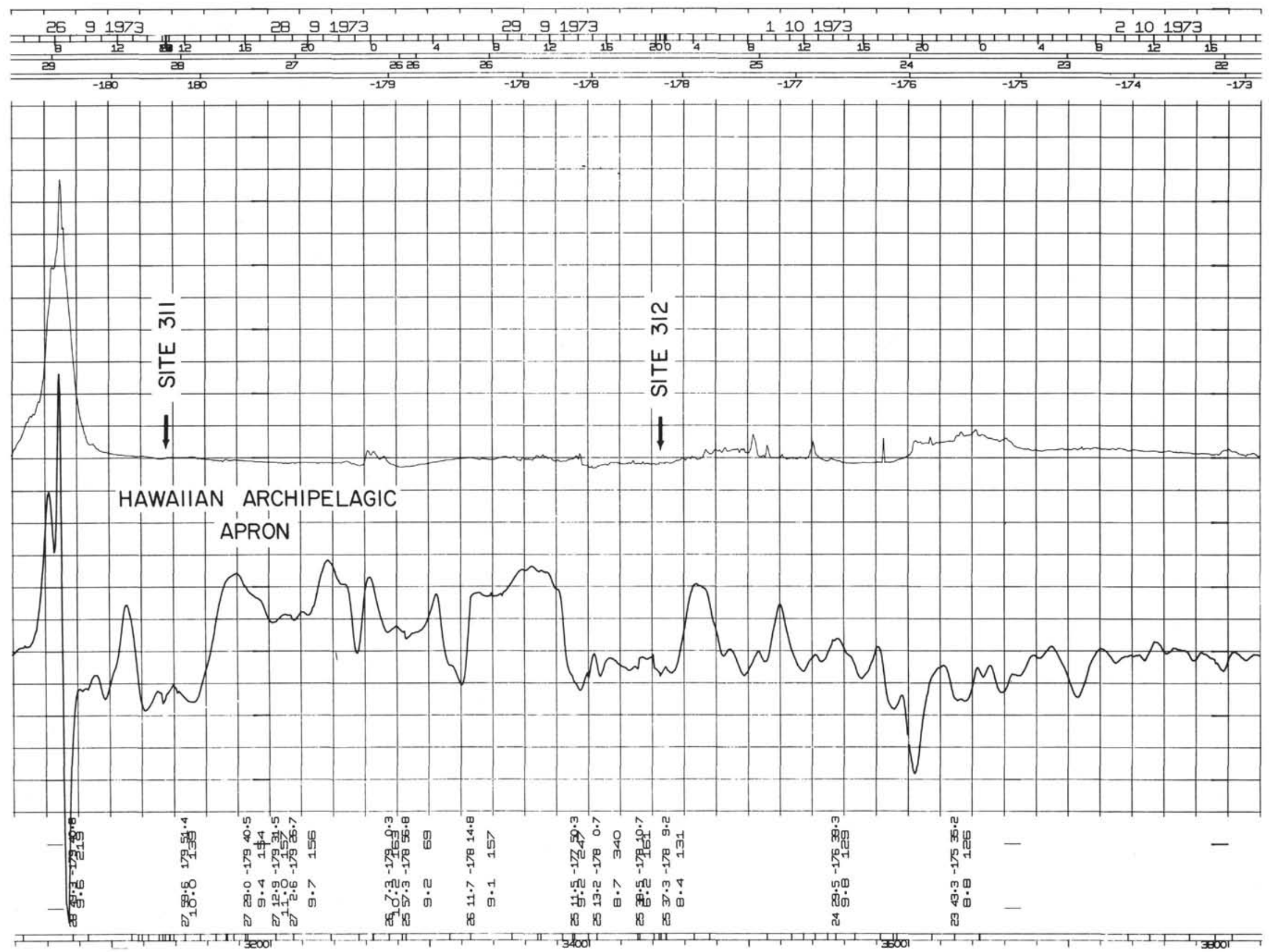



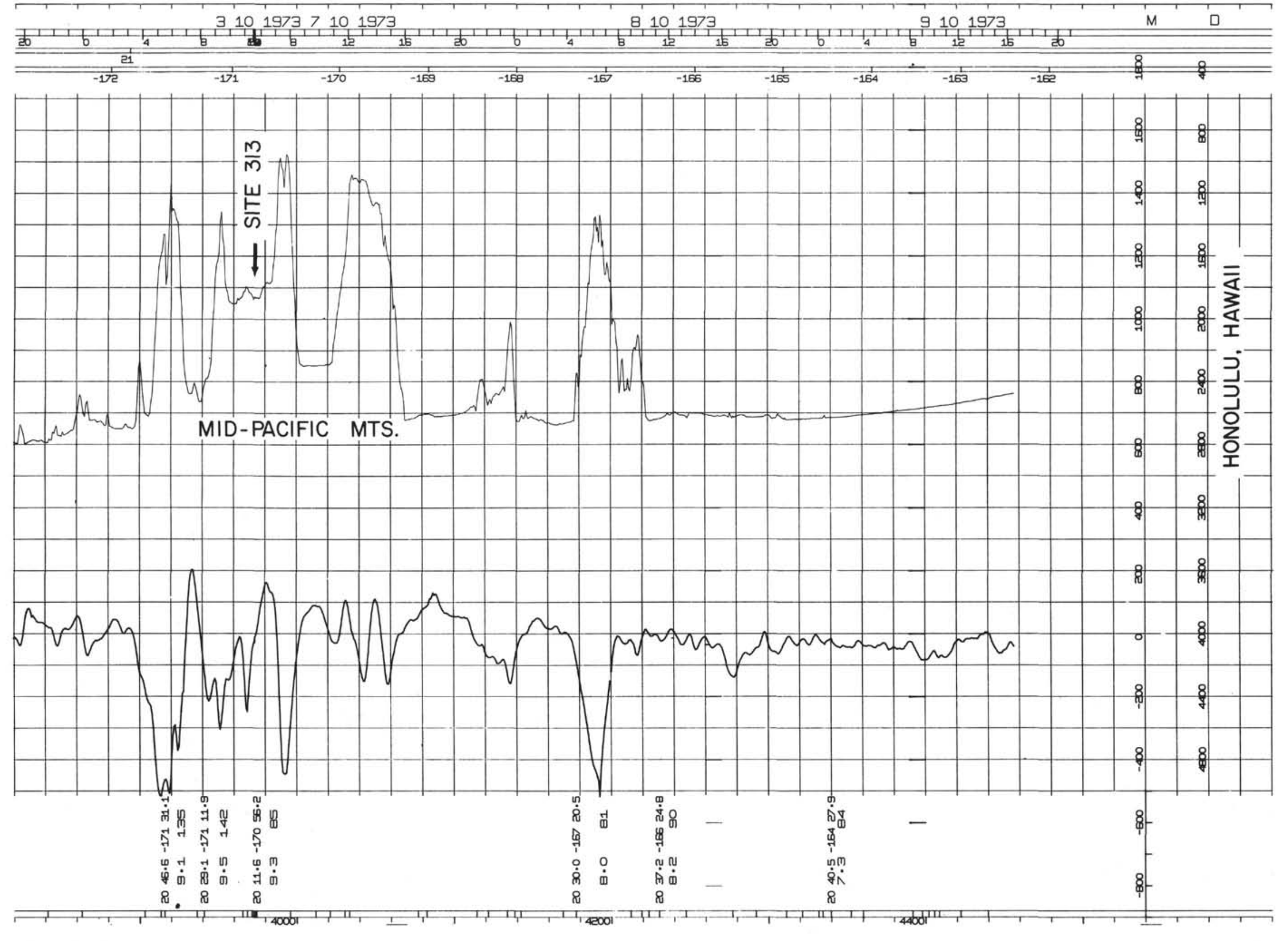

Figure 7. Magnetic anomaly and bathymetric profiles along the track of Leg 32 of Glomar Challenger. Plots and scales explained in text. 


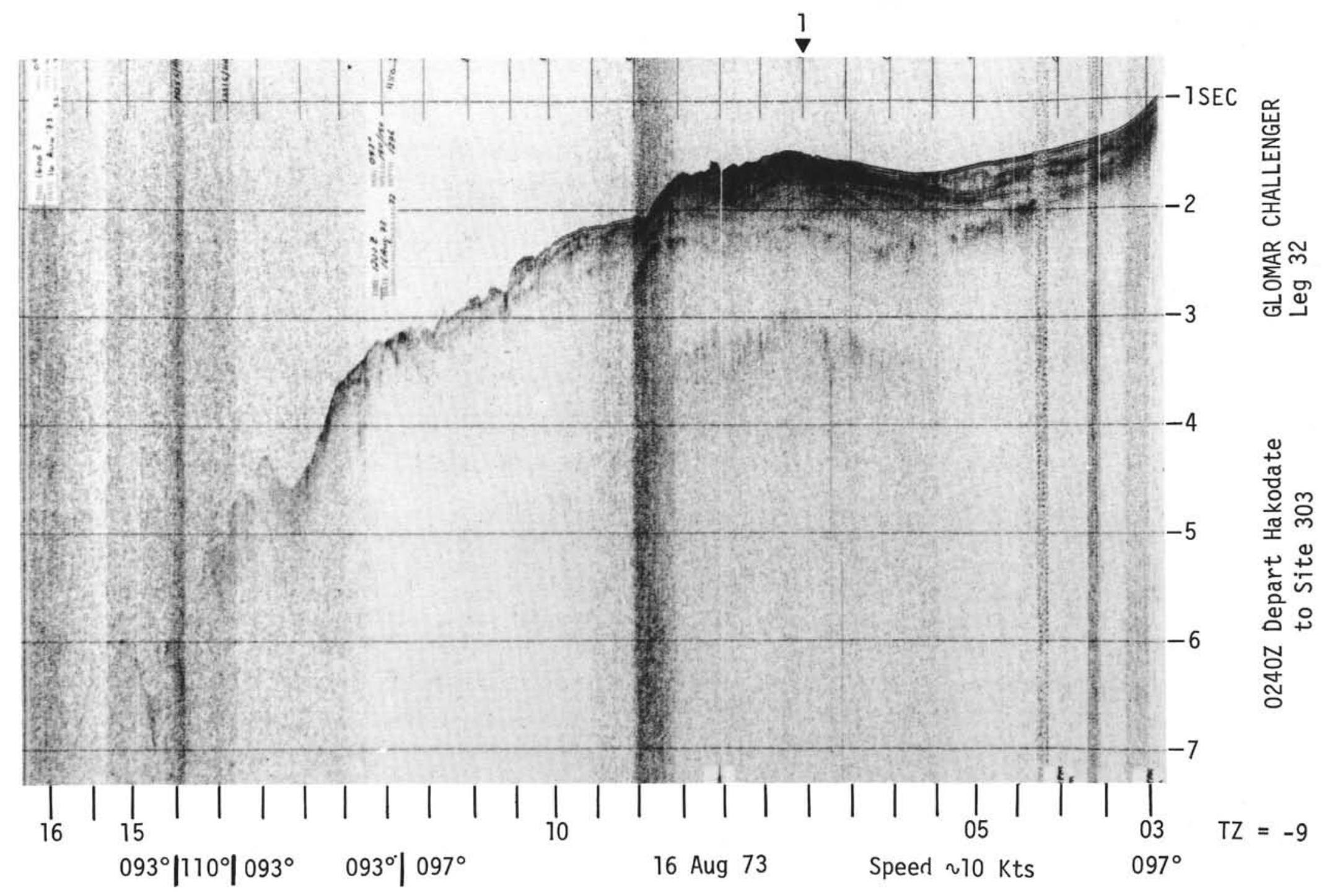

Figure 8. Seismic reflection profiles along the track of Leg 32 of Glomar Challenger. 


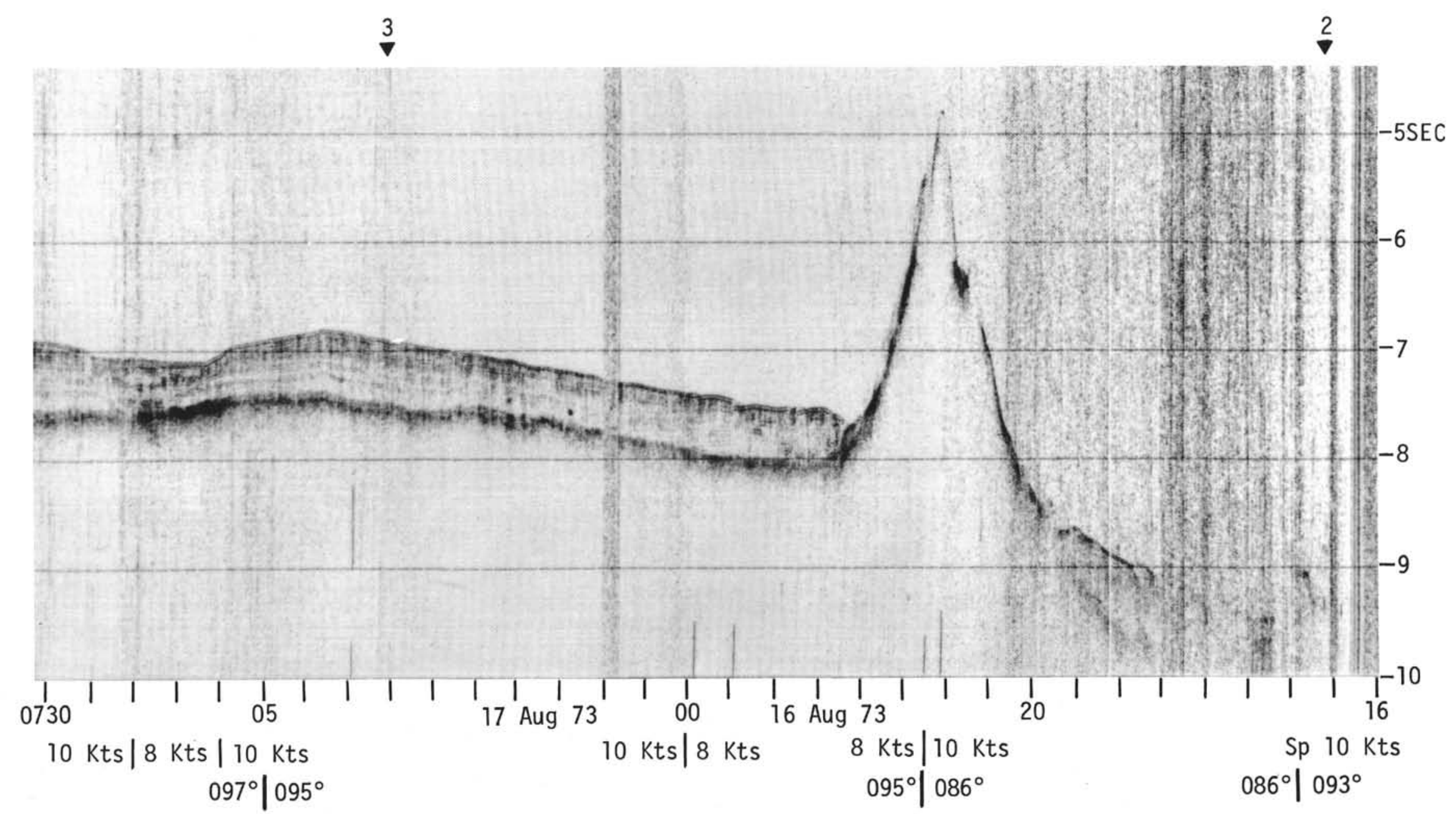

Figure 9. Seismic reflection profiles along the track of Leg 32 of Glomar Challenger. 


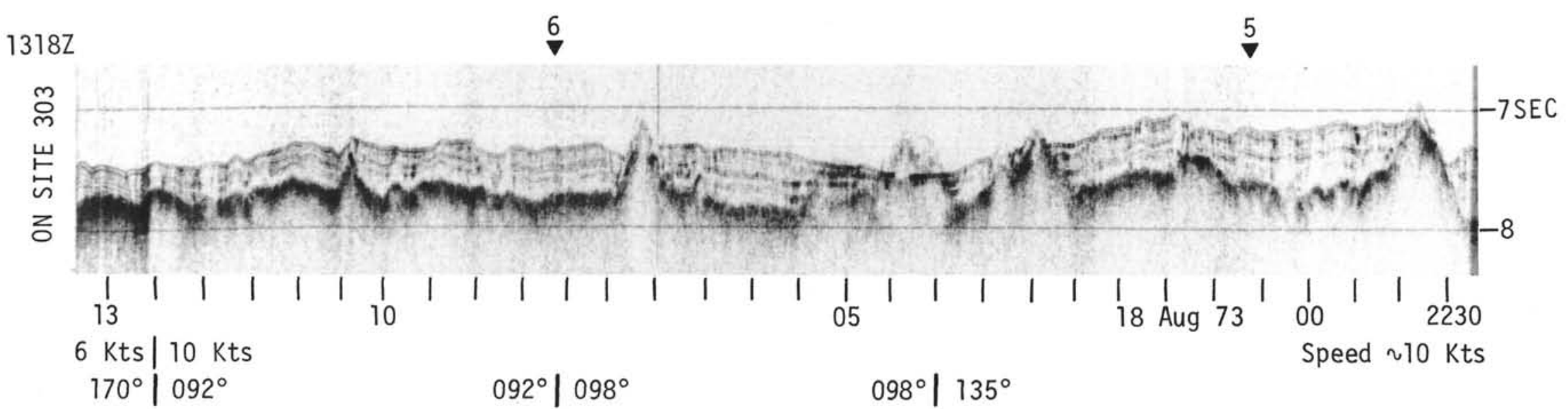

Figure 10. Seismic reflection profiles along the track of Leg 32 of Glomar Challenger. 


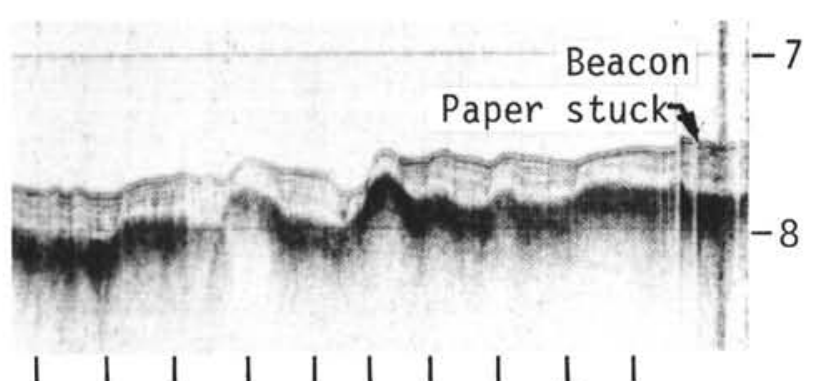

$\begin{array}{lllllllll}1 & 1 & 1 & 1 & 1 & 1 & 1 \\ 27 & \text { Aug } & 73 & 10\end{array}$

II
Speed $\sim 10 \mathrm{Kts}$ $166^{\circ} \mid 163^{\circ} \quad$ cse $163^{\circ}$

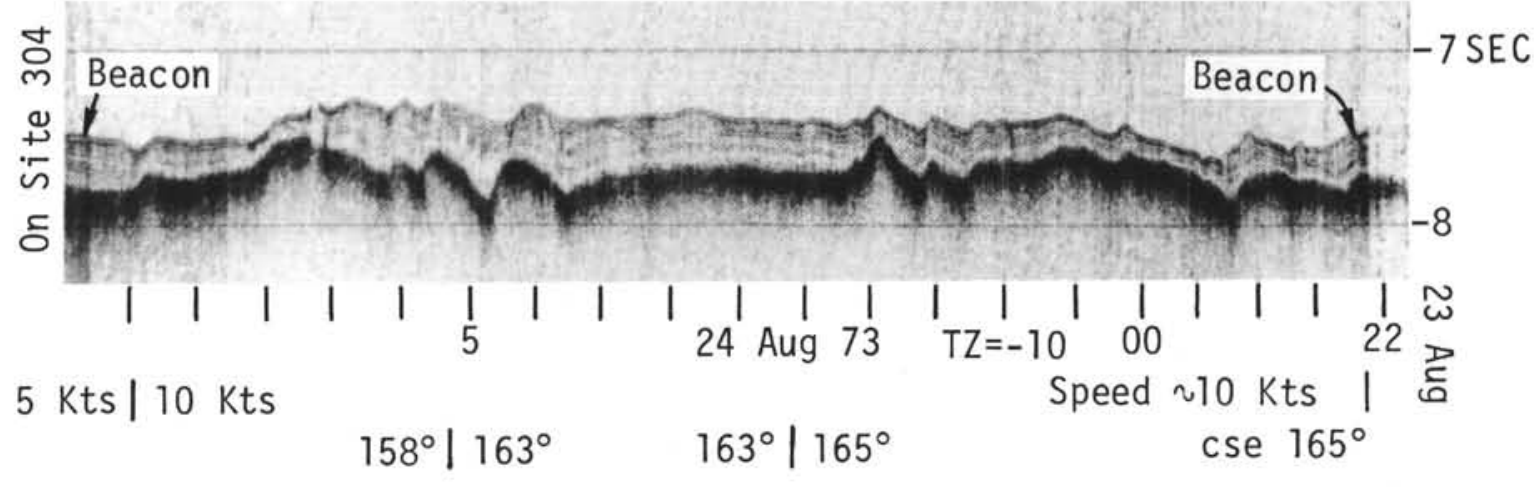

9

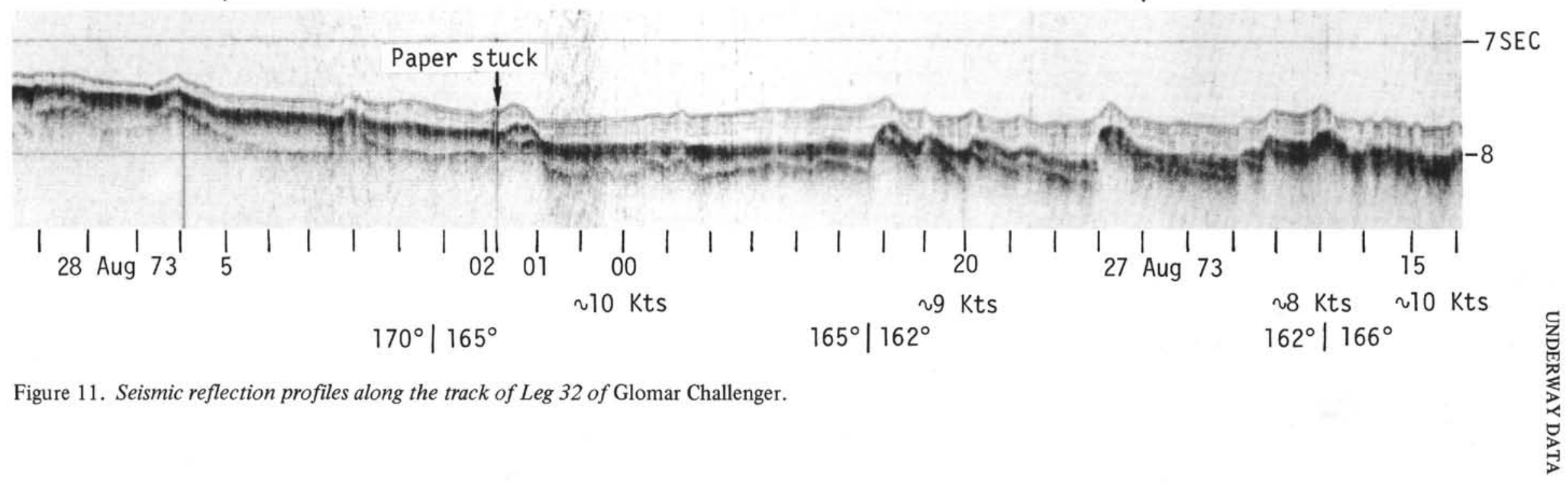



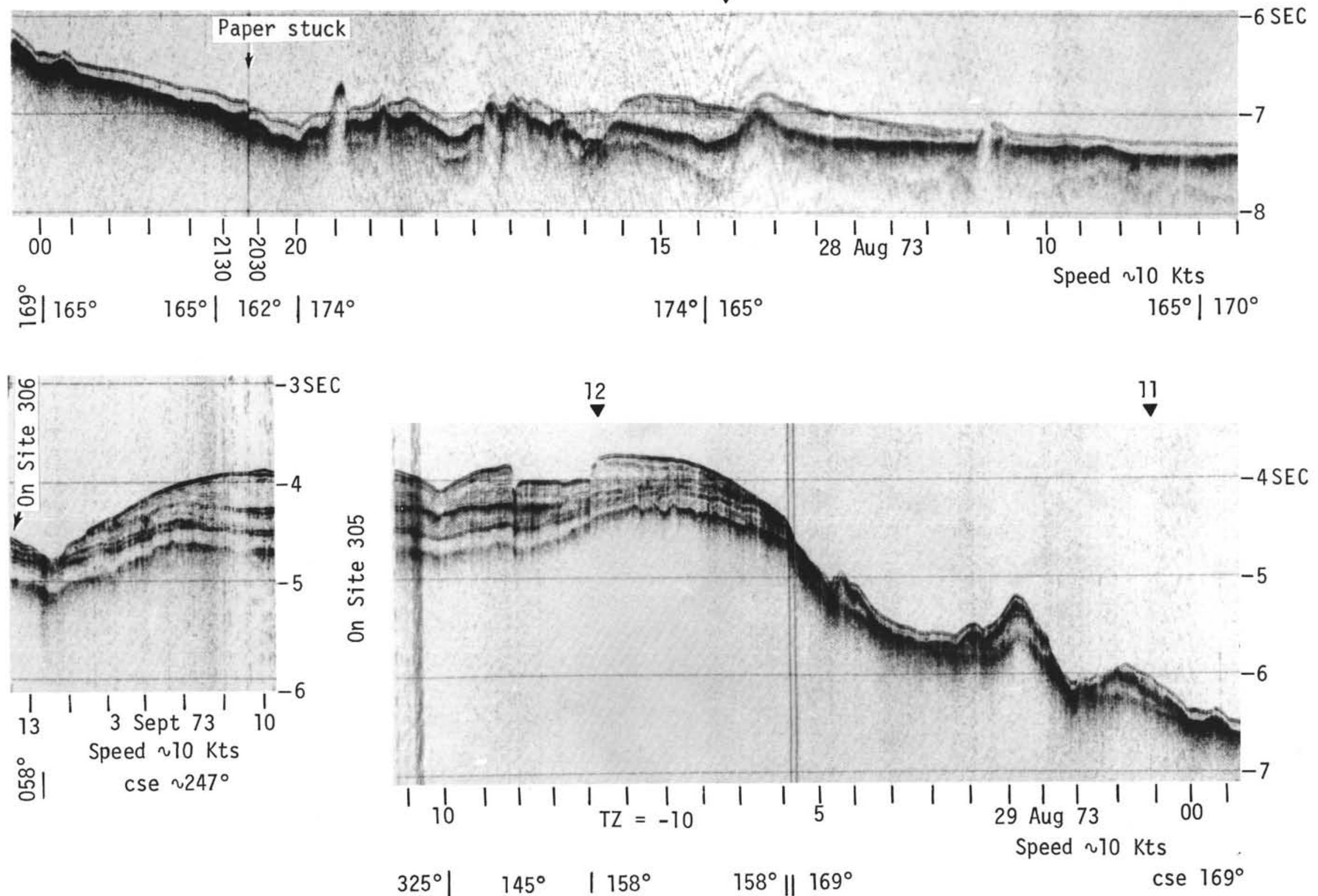

Figure 12. Seismic reflection profiles along the track of Leg 32 of Glomar Challenger. 

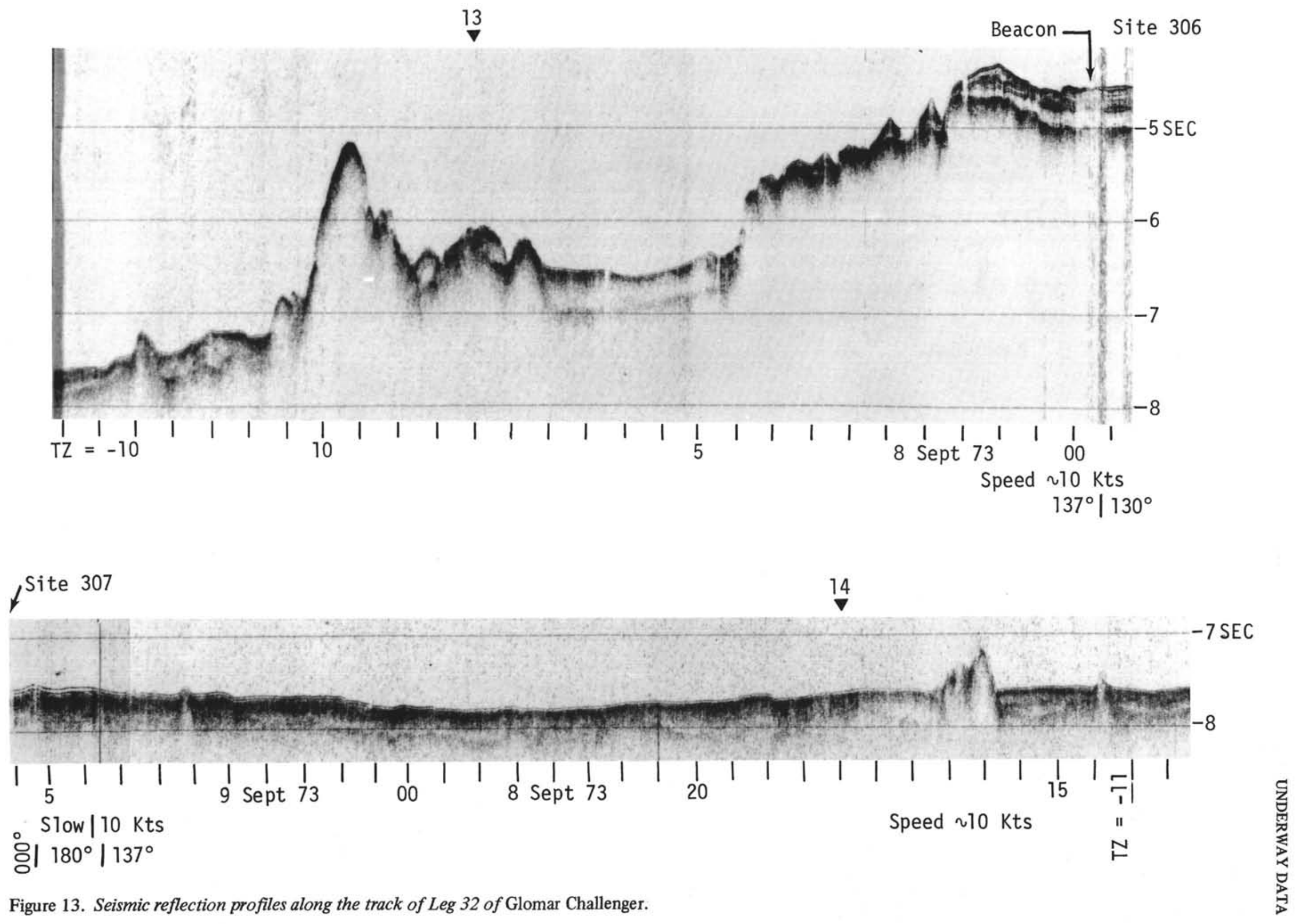

$\stackrel{ \pm}{\omega} \quad$ Figure 13. Seismic reflection profiles along the track of Leg 32 of Glomar Challenger. 

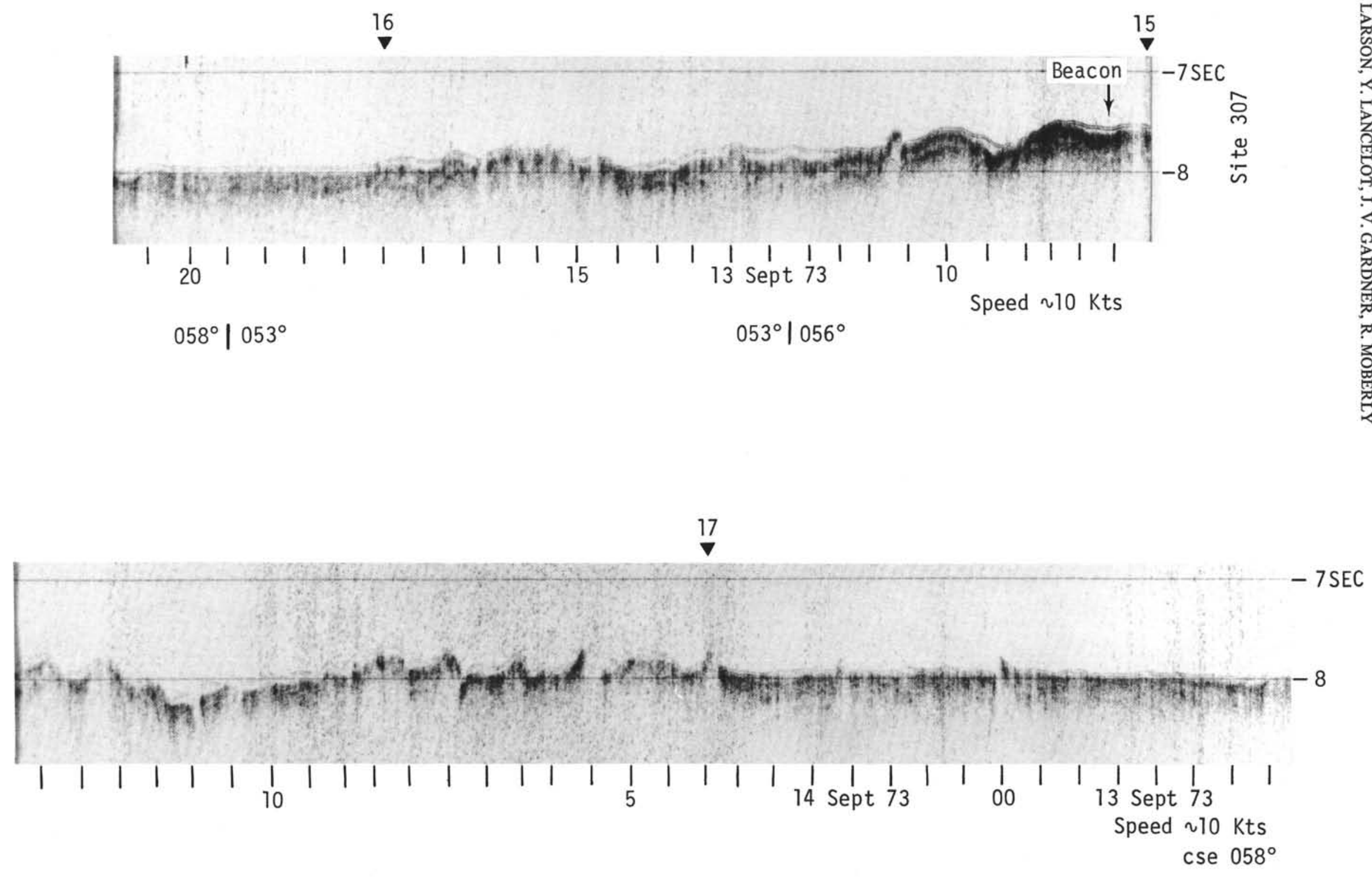

Figure 14. Seismic reflection profiles along the track of Leg 32 of Glomar Challenger. 

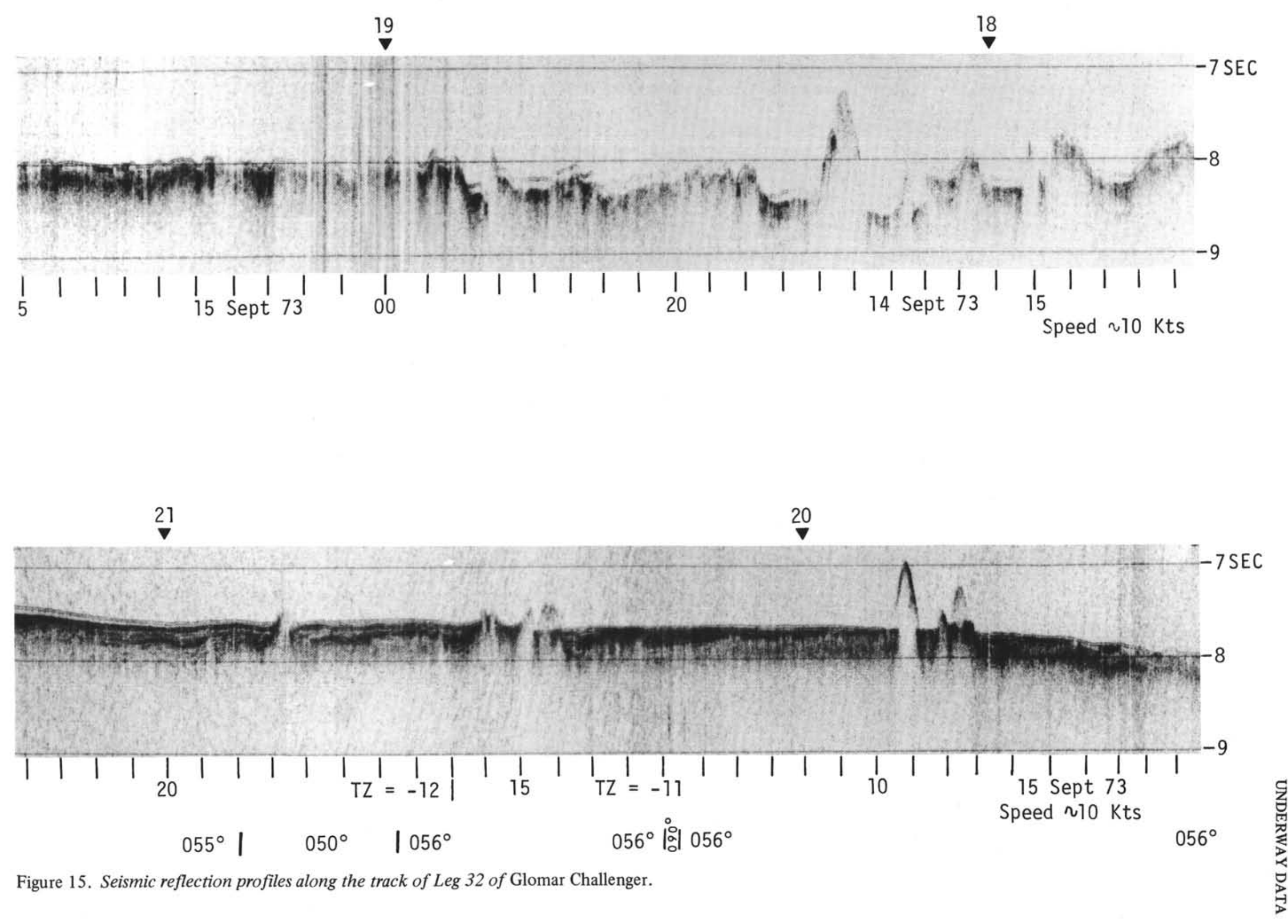

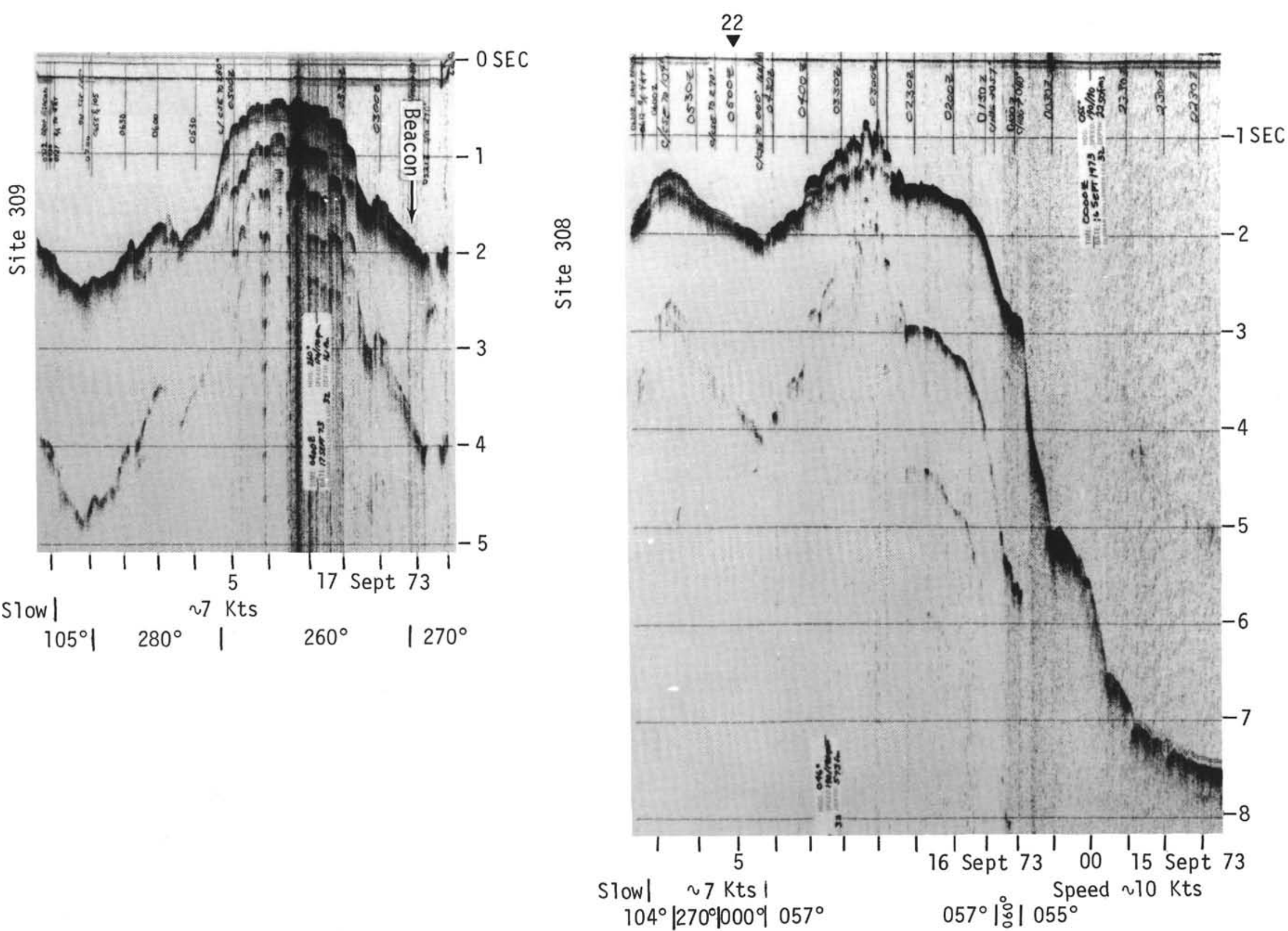

Figure 16. Seismic reflection profiles along the track of Leg 32 of Glomar Challenger. 


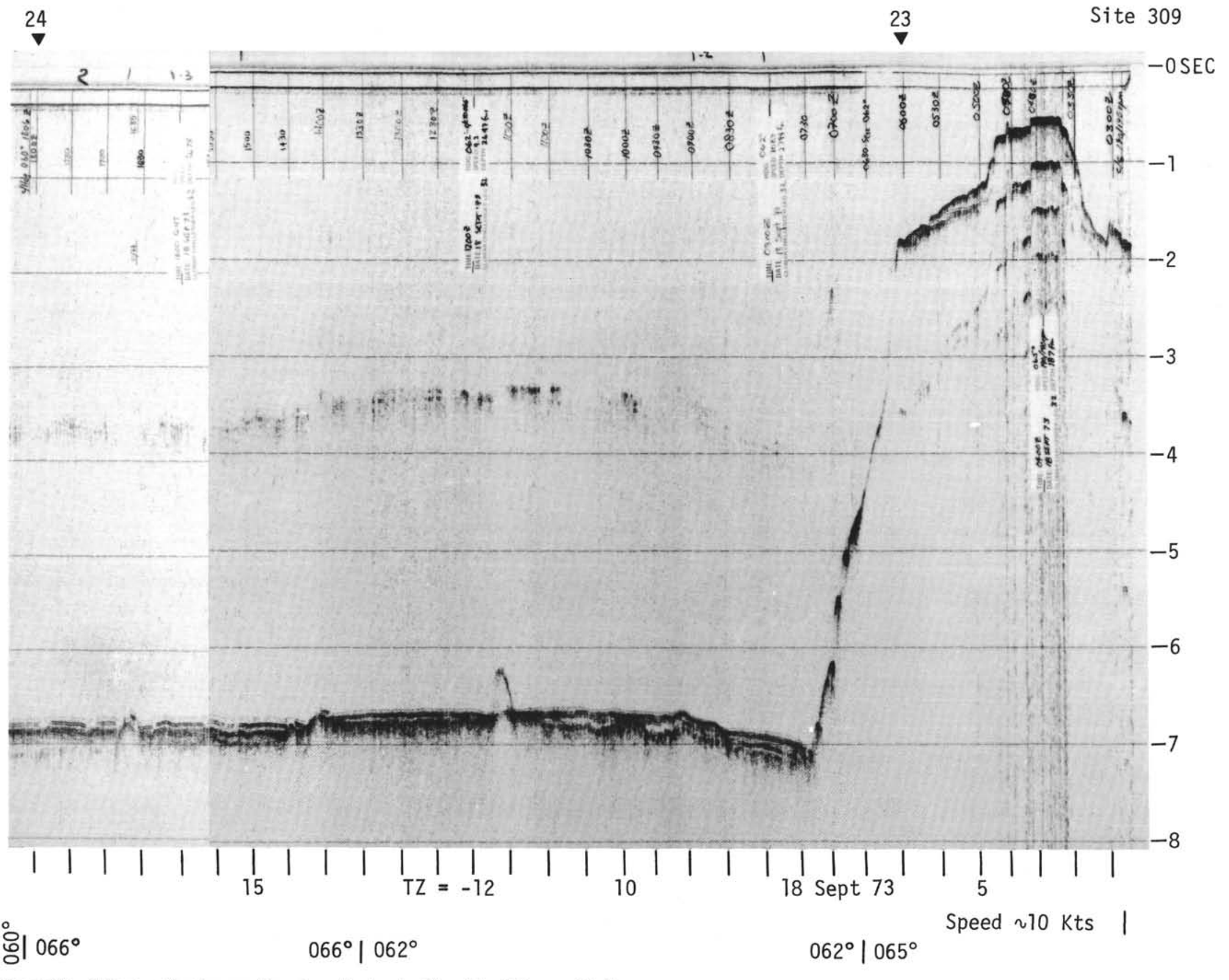



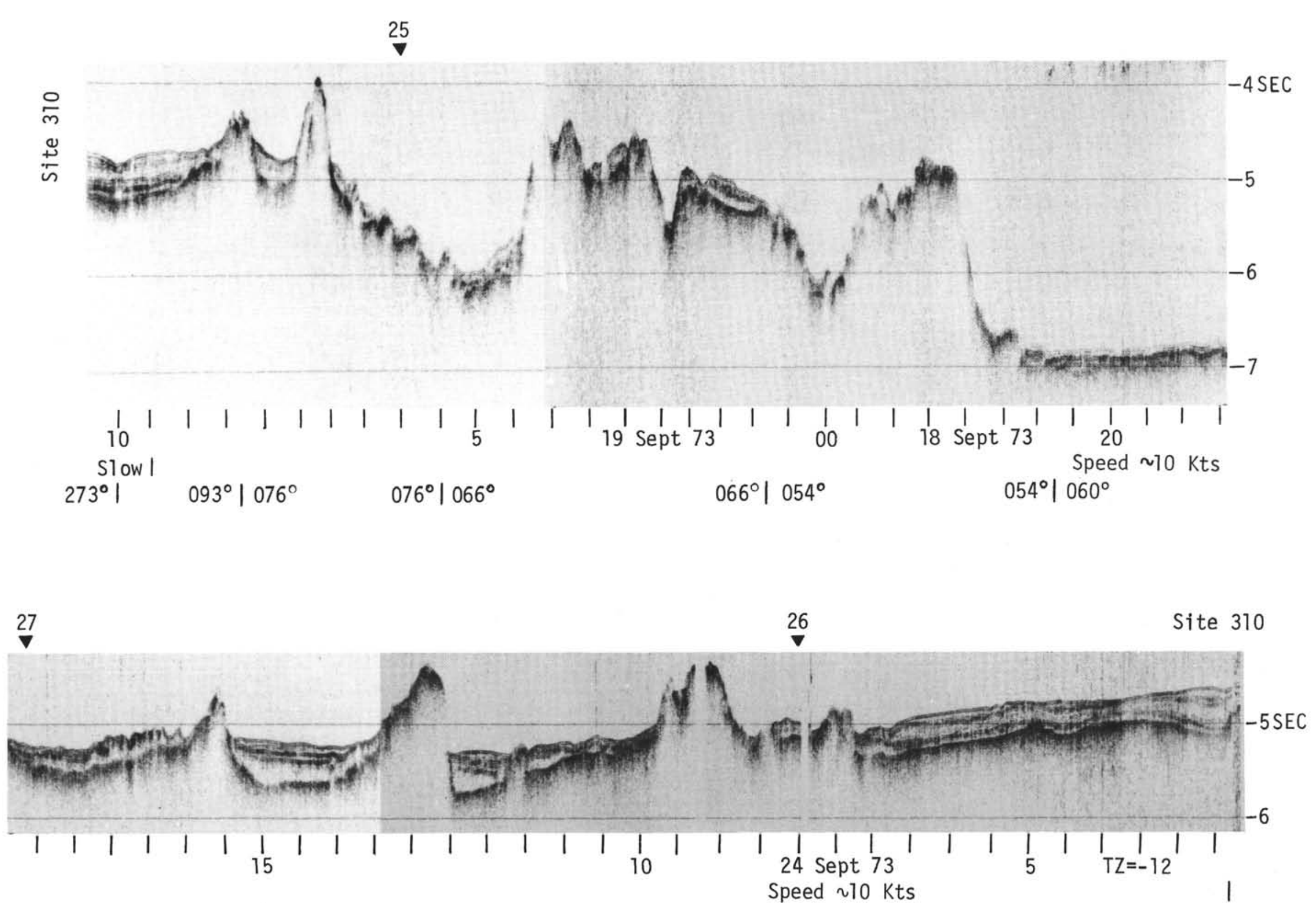
$155^{\circ} \mid 150^{\circ}$

Figure 18. Seismic reflection profiles along the track of Leg 32 of Glomar Challenger. 


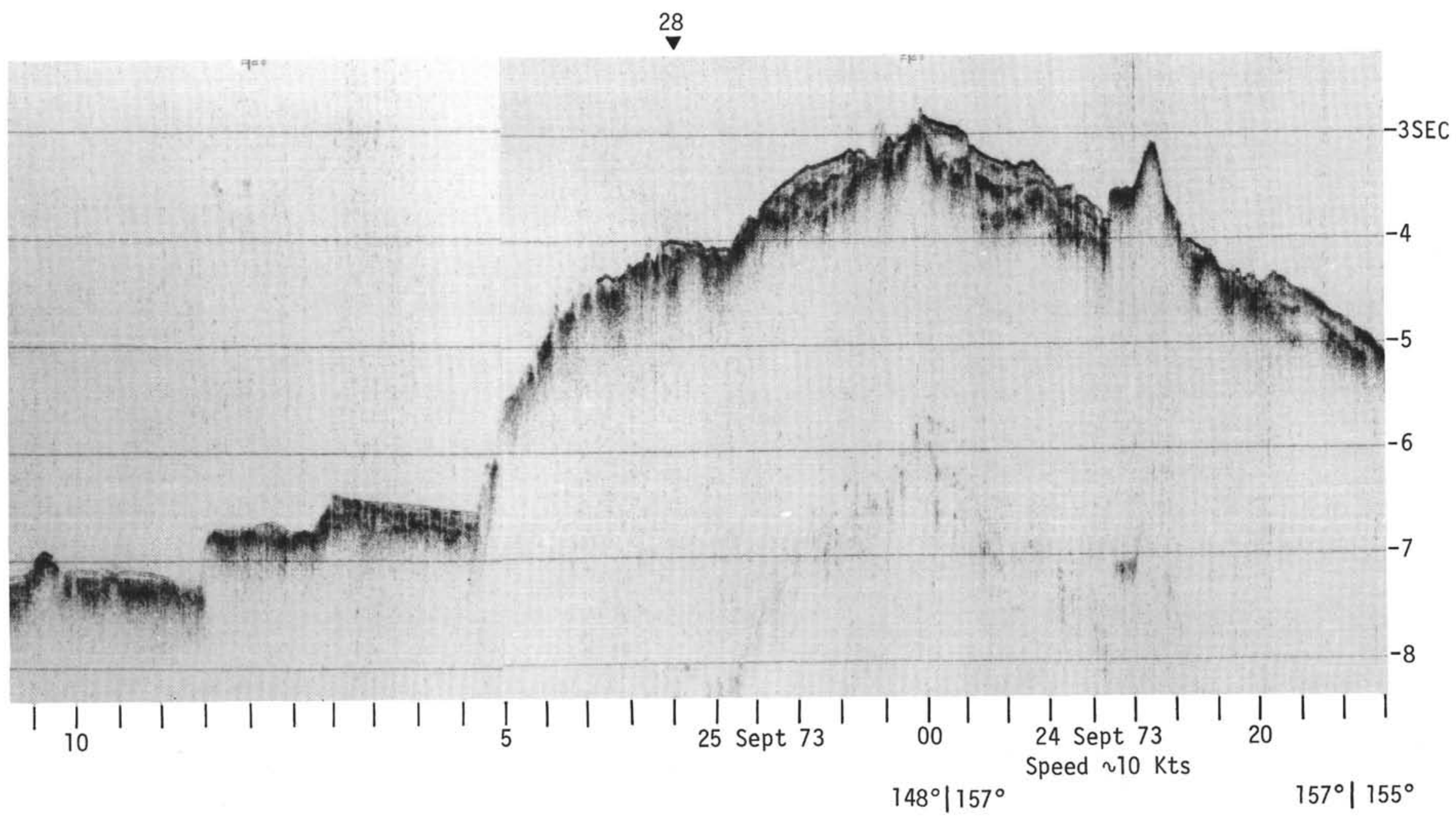

Figure 19. Seismic reflection profiles along the track of Leg 32 of Glomar Challenger. 


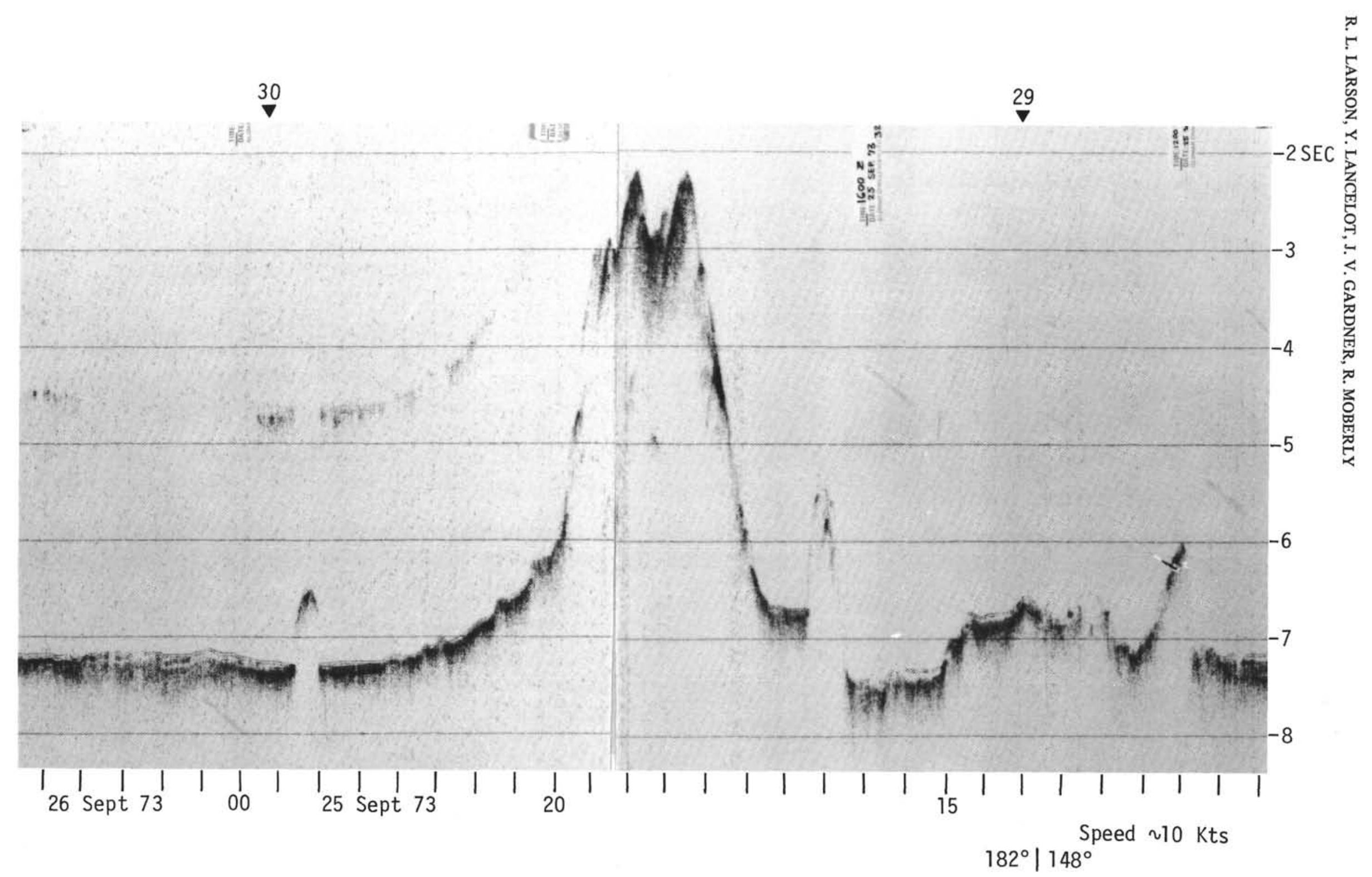

Figure 20. Seismic reflection profiles along the track of Leg 32 of Glomar Challenger. 


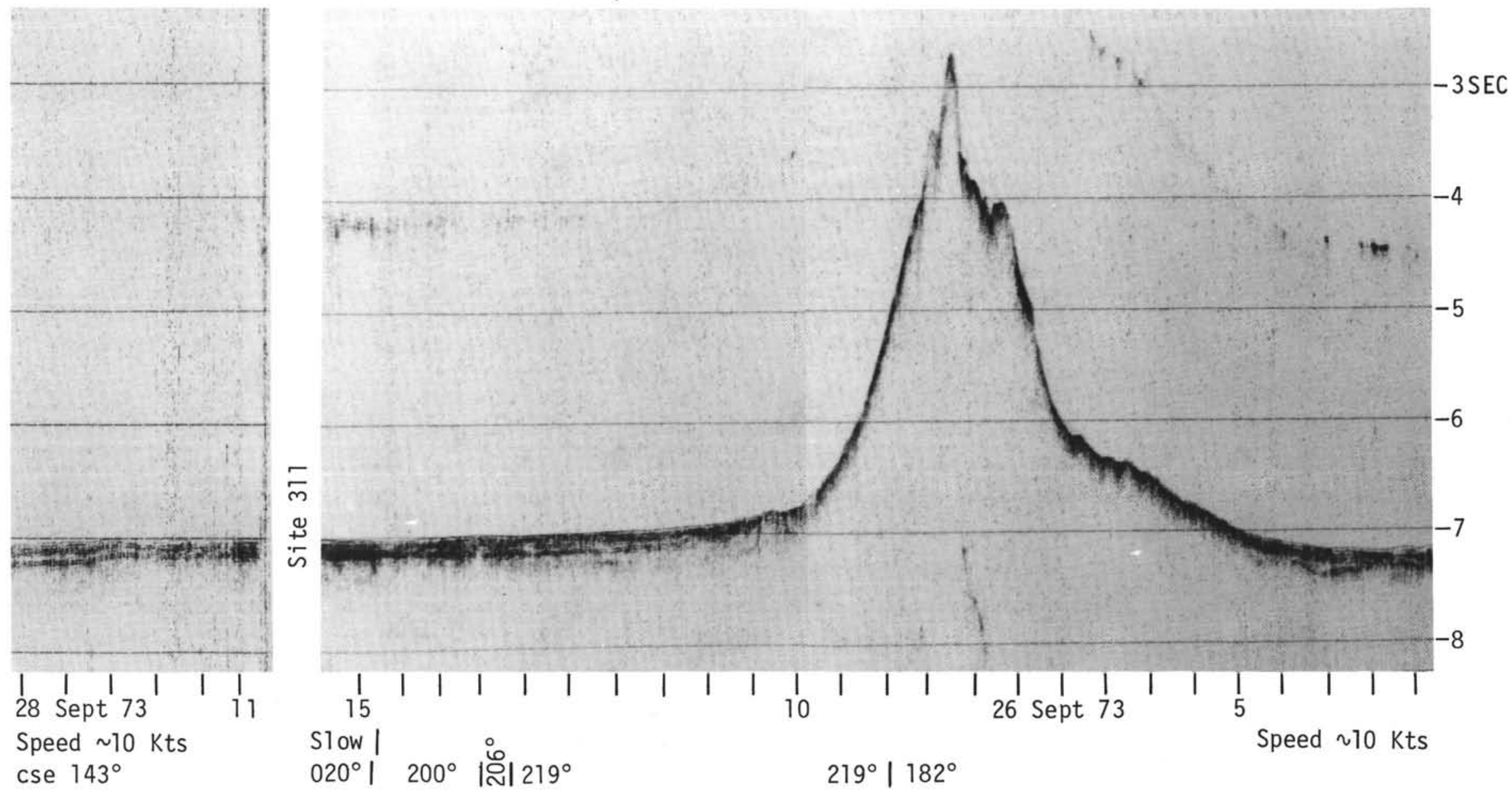

Figure 21. Seismic reflection profiles along the track of Leg 32 of Glomar Challenger. 


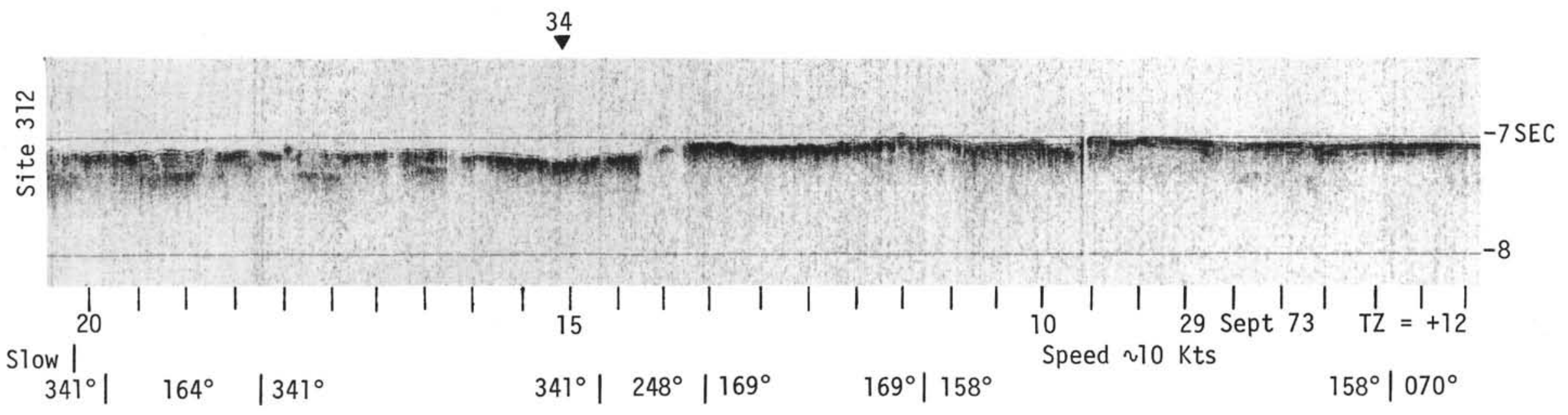

Figure 22. Seismic reflection profiles along the track of Leg 32 of Glomar Challenger. 

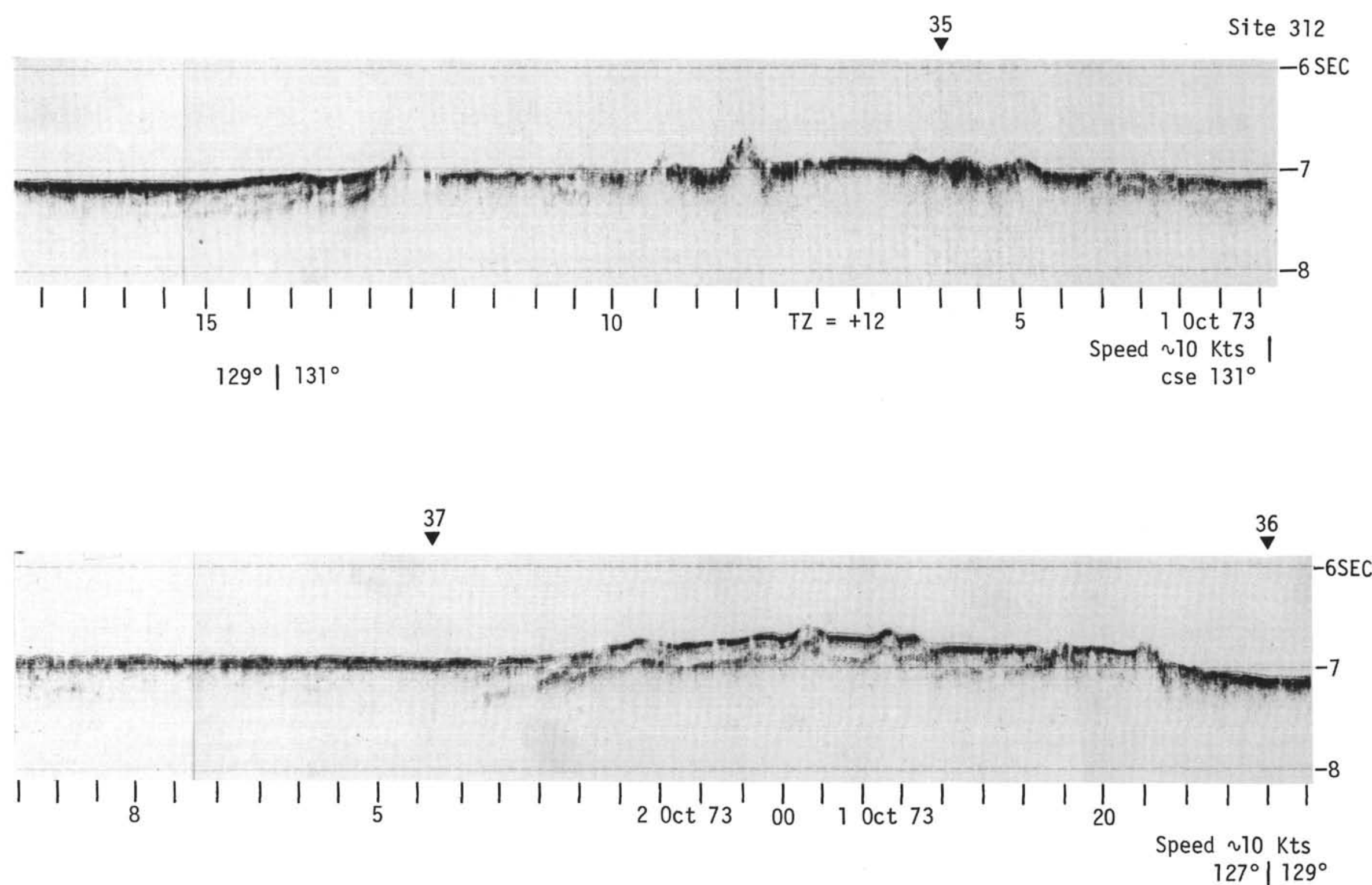

Figure 23. Seismic reflection profiles along the track of Leg 32 of Glomar Challenger. 

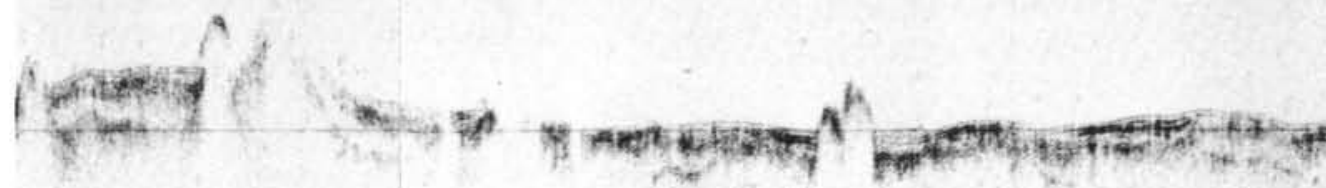

$\begin{array}{llll}-1 & 1 & 1 & 1\end{array}$

00

40

1 20

I

I

$\begin{array}{llll}1 & 1 & 1 & 1\end{array}$

$\frac{1}{15}$

11
$\begin{array}{lllllll}1 & 1 & 1 & 1 & 1 & 1 & 1 \\ 2 & \text { Oct } 73 & & & 10\end{array}$ Speed $\sim 9 \mathrm{Kts}$
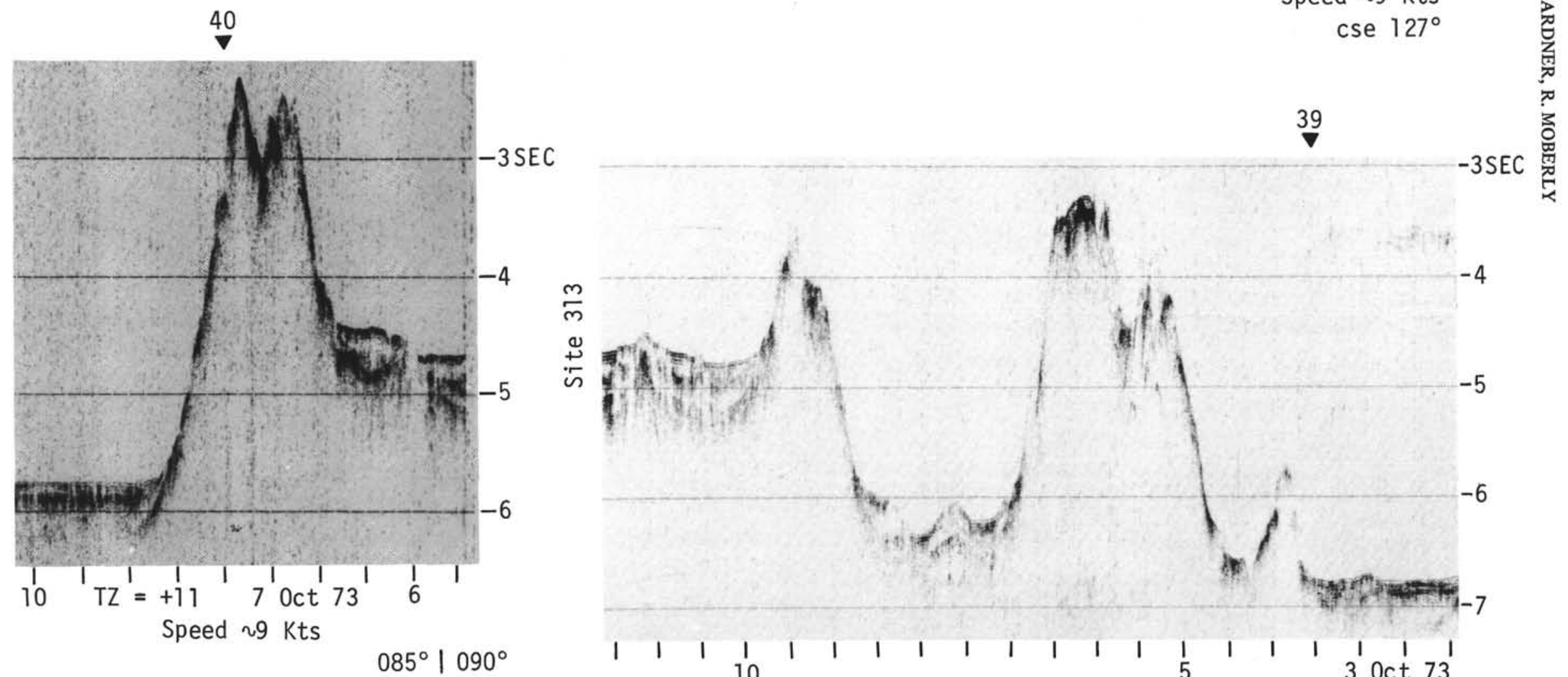

Slow

$$
326^{\circ}\left|146^{\circ} \quad 146^{\circ}\right| 127^{\circ}
$$

Figure 24. Seismic reflection profiles along the track of Leg 32 of Glomar Challenger. 


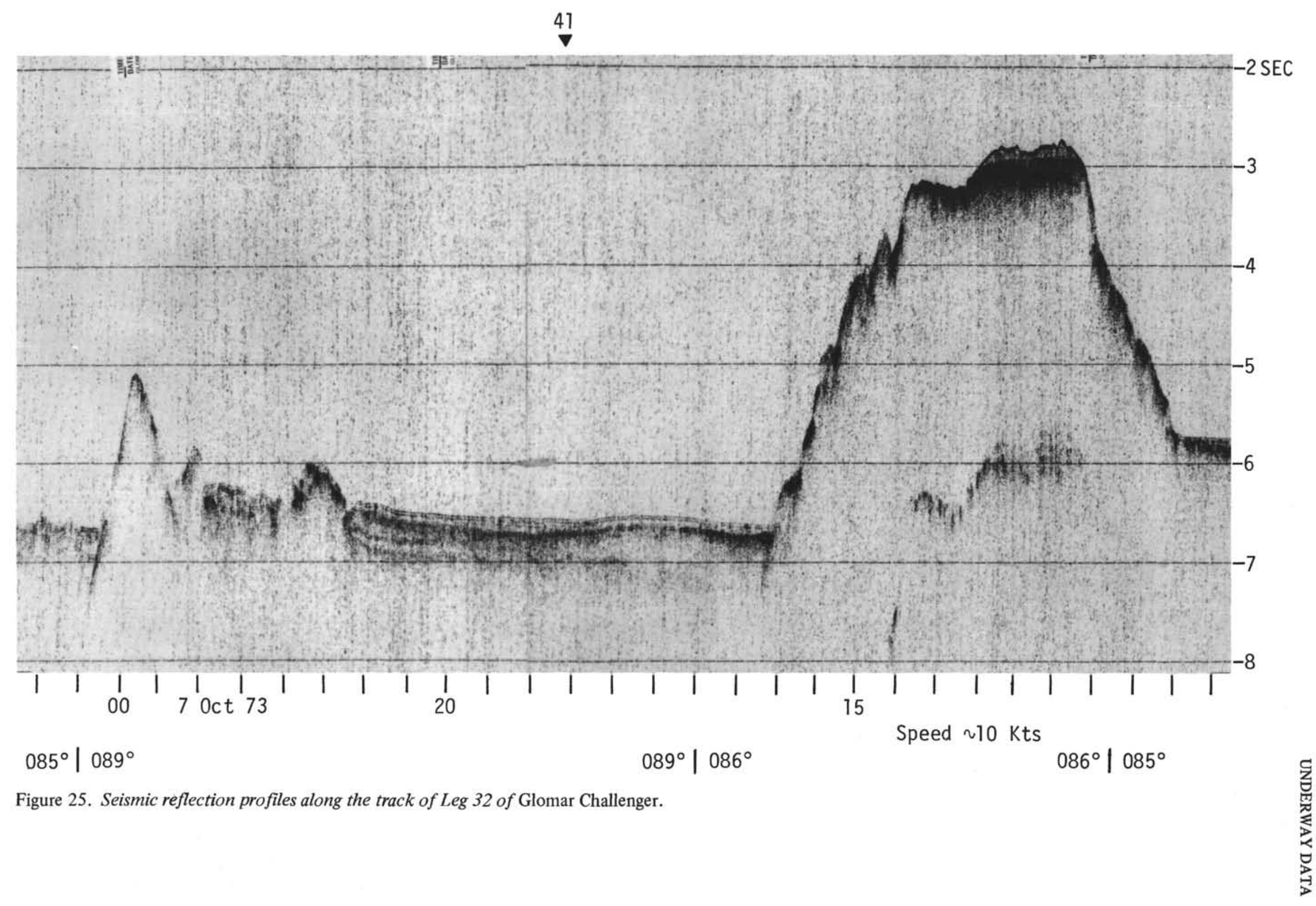




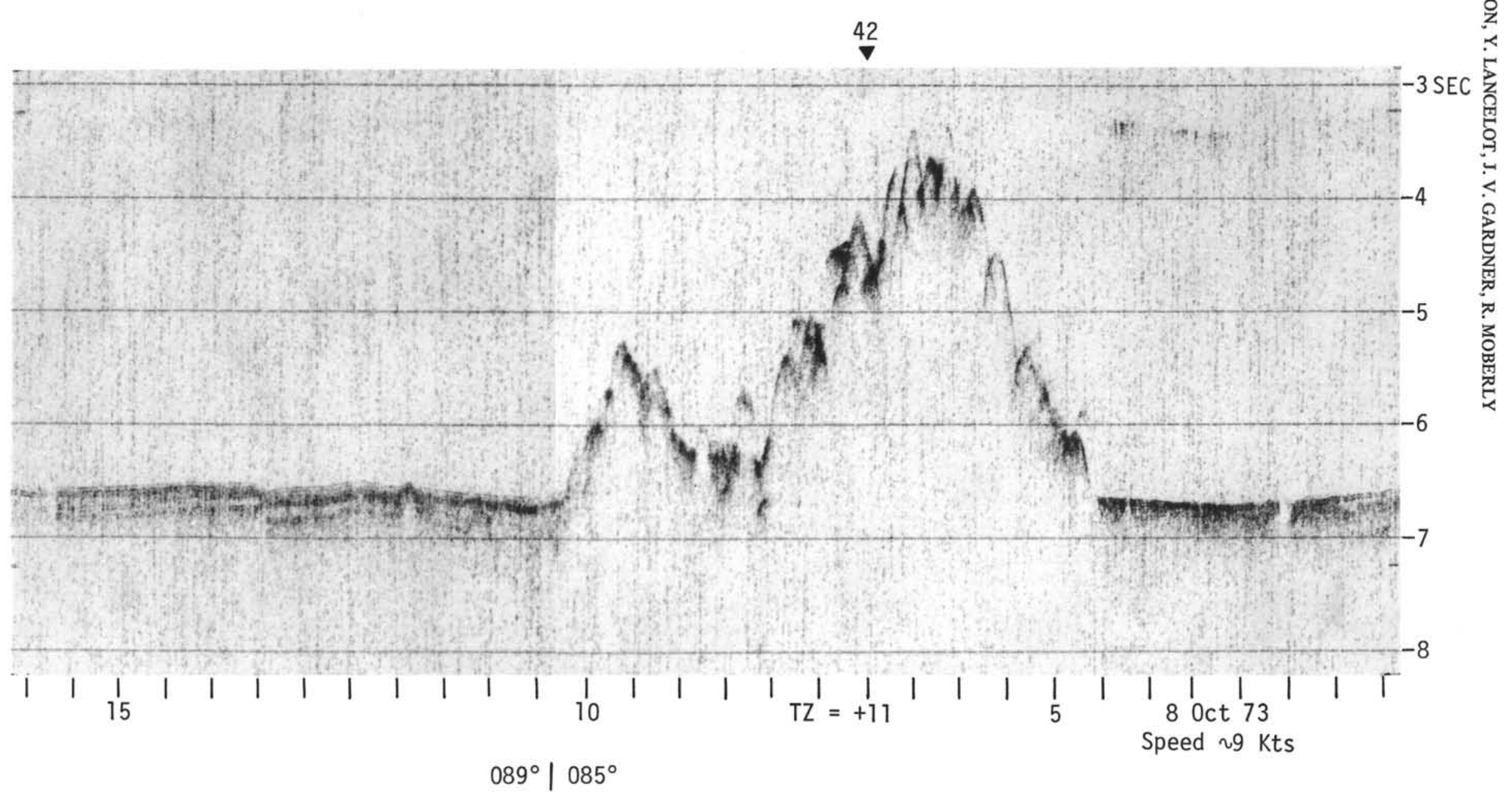

Figure 26. Seismic reflection profiles along the track of Leg 32 of Glomar Challenger. 


\section{3}
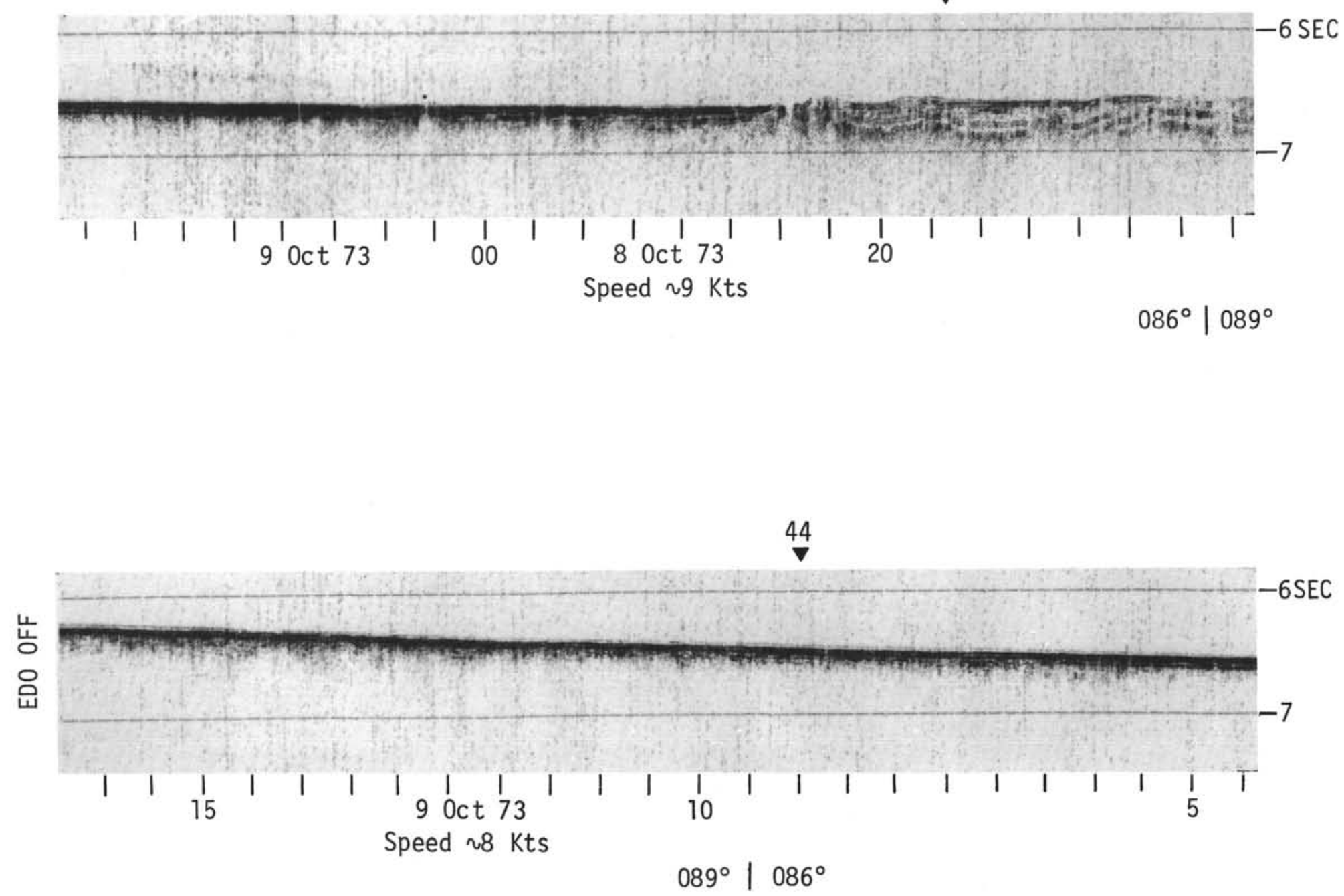

Figure 27. Seismic reflection profiles along the track of Leg 32 of Glomar Challenger. 